\title{
The Systems of Consumer Demand Functions Approach: A Review
}

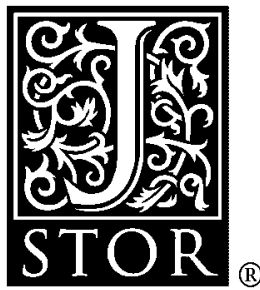

\author{
Anton P. Barten \\ Econometrica, Vol. 45, No. 1. (Jan., 1977), pp. 23-50.
}

Stable URL:

http://links.jstor.org/sici?sici=0012-9682\%28197701\%2945\%3A1\%3C23\%3ATSOCDF\%3E2.0.CO\%3B2-B

Econometrica is currently published by The Econometric Society.

Your use of the JSTOR archive indicates your acceptance of JSTOR's Terms and Conditions of Use, available at

http://www.jstor.org/about/terms.html. JSTOR's Terms and Conditions of Use provides, in part, that unless you have obtained prior permission, you may not download an entire issue of a journal or multiple copies of articles, and you may use content in the JSTOR archive only for your personal, non-commercial use.

Please contact the publisher regarding any further use of this work. Publisher contact information may be obtained at http://www.jstor.org/journals/econosoc.html.

Each copy of any part of a JSTOR transmission must contain the same copyright notice that appears on the screen or printed page of such transmission.

The JSTOR Archive is a trusted digital repository providing for long-term preservation and access to leading academic journals and scholarly literature from around the world. The Archive is supported by libraries, scholarly societies, publishers, and foundations. It is an initiative of JSTOR, a not-for-profit organization with a mission to help the scholarly community take advantage of advances in technology. For more information regarding JSTOR, please contact support@jstor.org. 


\title{
THE SYSTEMS OF CONSUMER DEMAND FUNCTIONS APPROACH:
} A REVIEW

\author{
By Anton P. BARTEN ${ }^{1}$
}

\begin{abstract}
This review of the work done on the formulation and estimation of complete systems of consumer demand functions is primarily concerned with problems and issues around this topic. These issues are partly of a theoretical and partly of an empirical nature. Constraints on such systems, derived from theoretical considerations, are used to deal with the problems of lack of sufficient data, but can sometimes also be tested. Among the various alternative approaches, as yet no clear-cut choice can be made, although it appears that additivity of preferences is too restrictive.
\end{abstract}

\section{INTRODUCTION}

LET $q$ BE AN $n$-vector of quantities of $n$ (finite) commodities and services, goods for short, desired or purchased by the consumer, and let $p$ be an $n$-vector of the prices per unit of those goods. Then one can write

$$
q=q(m, p)
$$

for the set of $n$ consumer demand functions, relating the quantities demanded to all prices and to $m$, which is defined by

$$
\text { ' } m=p^{\prime} q \text {. }
$$

From (1.2) it is clear that $m$ is total expenditure on the $n$ goods considered. This definition of $m$ makes (1.1) a complete set of demand functions.

Over a number of years a growing flow of research has been concerned with problems of specifying and estimating such systems. The earliest example is the incidental contribution by Leser (1941). After that more than a decade elapsed before the empirical application of the linear expenditure system by Stone (1954) appeared. The contribution by Somermeyer and Wit (1956) and especially that by Houthakker (1960) mark the end of the infant stage of the approach. Since then such systems of consumer demand functions have been the central theme of an almost continuous flow of articles and books. At present, it is virtually impossible to quote and summarize all contributions of the last fifteen years. In this review the emphasis will, therefore, be more on the essence of the approach, its possibilities, and its limitations. ${ }^{2}$

The approach is essentially an empirical one, in the sense that one aims at the formulation of a system to be estimated using actual data. In view of data limitations, one makes use of restrictions which, in part, are of a theoretical nature.

\footnotetext{
${ }^{1}$ Thanks are due to Michael D. Intriligator and anonymous referees who pointed out weaknesses in an earlier version. In a review like this, one is forced to be selective and, although some issues will be discussed at some length, others will be only mentioned in passing or are completely left aside. Some contributors to the development of the approach might feel that their work has not been given the attention it deserves. The desire to remain concise and sheer lack of knowledge and insight on the side of the author are to be blamed.

${ }^{2}$ For more information reference is made to the survey by Brown and Deaton (1972) and to the monographs by Powell (1974), Phlips (1974), and Theil (1975a, 1976).
} 
In most empirical applications, $m$ and $p$ are taken to be exogenously given. Then (1.2) provides clearly a constraint on (1.1). Further constraints are taken from the theory of consumer demand. The use of such constraints is, in part, inspired by the desire to arrive at results which can be given a theoretical interpretation, but, more often than not, the restrictions serve to reduce the dimensionality of the estimation problem and to deal with certain shortcomings of the available data.

Actual data usually refer to consumption for a limited number of highly aggregated groups of goods, for a whole economy, and for a relatively small number of years. The theory of consumer demand, however, is about individual behavior with respect to the choice of quantities of a potentially large number of elementary goods. Strictly speaking, a number of aggregation conditions should be fulfilled to formulate demand equations in terms of the aggregated observations. For most available data sets, however, it is virtually impossible to verify the empirical validity of such aggregation conditions.

Even if one would have time series information on demand for individual goods, some aggregation over these goods would be needed to reduce the dimensionality of the system for purposes of estimation. Many of the published applications are indeed about systems of less than ten major groups of goods; a large number are limited to three or four of such groups. Even then, a considerable degree of multicollinearity among the prices calls for restrictions to avoid nonsensical point estimates.

Empirical application requires the specification of the functional form of the demand equations. Various approaches have been used, each with its specific merits. The nature of the data prevents a clear-cut decision about the empirical superiority of any particular choice. Other criteria are used, like convenience, generality, and theoretical relevance. It depends on the preferences, the aims, and the (vested) interests of the researcher as to which approach he will pursue, and one is still far from a consensus on the issue of the ideal functional form.

Some of the theoretical constraints, and also (1.2), imply constraints across equations. To take these explicitly into account all equations have to be estimated jointly. Estimation methods like maximum likelihood or the Zellner (1962) variant of generalized least squares are indicated here to benefit fully from the increase in efficiency of the estimators when the constraints are empirically valid. Such simultaneous estimation methods require the existence of a nonsingular covariance matrix estimator for the disturbances of the equations of the system. Usually, an unconstrained estimator is employed. However, (1.2) implies a linear dependence of the joint distribution of the disturbances if $m$ and $p$ are exogenous. The theoretical covariance matrix is, therefore, singular. This problem is usually solved by deleting one equation from the system. Still, the requirement that the estimated covariance matrix of the reduced system is nonsingular implies that the number of observations be at least as large as the number of equations in the system if one formulates no further constraints on the covariance matrix. ${ }^{3}$ Given

\footnotetext{
${ }^{3}$ To estimate the linear expenditure system with 37 commodity groups on the basis of annual data for the United Kingdom for 17 years, Deaton (1975) uses an a priori specified covariance matrix to deal with this problem.
} 
the lack of long time series such simultaneous estimation methods are limited to systems with a relatively small number of groups of goods.

It is usually assumed that the equations of (1.1) are identified as demand functions. Supply functions are supposed to contain determinants which are absent from (1.1). Moreover, it is implicitly assumed that, at the existing prices, consumers can buy what they can afford given their means. The possibility of nonprice rationing is usually not considered.

In this introduction various aspects of the specification and estimation of demand systems have been briefly discussed. Some of these will be taken up in more detail in the following sections. It is useful to accentuate the empirical orientation of the approach. It aims at the combination of empirical and theoretical considerations in a pragmatic blend. The role of the theory is to support empirical analysis. The present state of the art prevents one from arriving at a conclusive test of the empirical validity of the underlying theory. Moreover, the approach is primarily concerned with the interdependency of demand for the various goods. It is not necessarily the only way to describe empirical demand behavior. In case one is interested in demand for a single good only, other approaches might be pragmatically more suitable. The main feature of the approach is the structuring of the interdependencies. If these interdependencies are deemed to be of secondary or less importance, the complete set approach will not be worthwhile and attention can be concentrated on other aspects.

\section{GENERAL CONSTRAINTS ON THE SYSTEM}

It is generally assumed that the demand system $q(m, p)$ is differentiable with respect to $m$ and $p$. In differential form the system can be written as

$$
d q=q_{m} d m+Q_{p} d q,
$$

where $q_{m}$ is the $n$-vector of derivatives with respect to $m$, and $Q_{p}$ is the $n \times n$ matrix of derivatives with respect to $p$. Likewise, the differential version of (1.2) is

$$
d m=p^{\prime} d q+q^{\prime} d p .
$$

Some constraints can be formulated directly on (1.1) or in terms of its derivatives; others are more naturally defined on the derivatives. In this section the adding-up, the homogeneity, the symmetry, and the negativity conditions will be discussed.

\section{A. Adding-up Condition}

The adding-up condition follows from the simultaneous validity of (1.1) and (1.2) or, alternatively, of (2.1) and (2.2). In terms of derivatives this condition amounts to

$$
p^{\prime} q_{m}=1, \quad p^{\prime} Q_{p}+q^{\prime}=0 .
$$


The way the data have been constructed usually guarantees that they satisfy (1.2). Estimated versions of the demand systems either satisfy the adding-up condition automatically or on the average for the sample period depending on the type of functional form used. In the latter case, problems might arise when extrapolating the system some distance away from the sample averages. Then, the sum of the components might be seriously different from the total.

It is useful to pay some attention to the meaning of $m$. By definition it is the sum of expenditures on the components of the vector $q$. In most applications $q$ is taken to be demand on nonfinancial goods per year. Then $m$ is total consumer expenditure per year. If one of the elements of $q$ is (dis)saving, $m$ can be considered income. However, in principle, $q$ can contain also leisure-see, e.g., Diewert (1974b). Then, if savings are also included, $m$ has the meaning of "full" income. In an intertemporal context, $m$ can be given the interpretation of total wealth. One can also limit $q$ to a subset of consumer goods during a certain period, say demand for food. Then $m$ has the meaning of expenditure on food for that period. What matters is that $m$ is formally taken to be given prior to the decision of how to spend it on the set of goods in question, as described by (1.1), which is sometimes also called a consumption allocation model.

This way of treating $m$ also has consequences for the random part of the demand system. Assuming an additive random disturbance vector $v$ with mean $a$ and covariance matrix $\Omega$, one has

$$
q=q(m, p)+v .
$$

Use of (1.2) yields

$$
p^{\prime} q=p^{\prime} q(m, p)+p^{\prime} v=m .
$$

Consequently, $p^{\prime} v$ is by definition zero. ${ }^{4}$ This means that the vector of disturbances is linearly dependent and that

$$
p^{\prime} a=0, \quad p^{\prime} \Omega=0 .
$$

The covariance matrix of the system is singular and generally nonscalar. Also, the estimated residuals will satisfy $p^{\prime} \hat{v}=0$ if at least the functional form satisfies exactly the adding-up condition for the nonrandom component of the system. If this is not the case, the degeneracy is masked, but it is, in principle, still there.

In practice, the problem amounts to the redundancy of one equation in the system. For given $m$ and $p,(1.1)$ and (1.2) define a system of $n+1$ relations among $n$ unknowns. One can delete any of the $n$ relations from (1.1) without loss of information on the demand behavior for the good for which the relation has been dropped. In the context of estimation this has been shown formally by Barten (1969), Solari (1971), and Berndt and Savin (1975).

${ }^{4}$ If $m$ is incorrectly assumed to be exogenous but in fact jointly determined with $q, p^{\prime} v$ is still by definition zero, but the random component of $m$ is correlated with that of $q$. This point has been elaborated by Lluch (1973) in the context of an intertemporal allocation problem where $m$ is given the interpretation of consumer expenditure in a given period. However, if one can decompose the intertemporal allocation decision process into two levels: one where it is decided what to spend on consumption in each period and one where, conditional on the first decision, it is decided how to spend this, such a correlation would be absent. 


\section{B. Homogeneity Condition}

The homogeneity condition amounts to the assumption that the demand equations are each homogeneous of degree zero in $m$ and $p$, or, for a positive $\alpha$,

$$
q=q(\alpha m, \alpha p) .
$$

Using Euler's theorem, this condition can be written in terms of derivatives as

$$
q_{m} m+Q_{p} p=0 .
$$

The use of this condition has the consequence that one eliminates the consequences of inflation. This might be attractive as long as consumer demand is indeed insensitive to inflationary movements. This might be more true in the long run than in the short run.

The homogeneity condition is based on the assumption that the individual consumer makes his decisions irrespective of the monetary unit of account. This implicitly means that $q$ does not contain pure monetary goods. Moreover, even if this condition is satisfied for the individual consumer it only holds for the aggregate under rather special conditions for the income distribution. Several authors have tried to test the validity of the homogeneity condition on the aggregate level when estimating their demand systems and have frequently had to reject it. Ignoring this condition altogether might cause problems for the extrapolation of demand under conditions of strong inflation not experienced during the sample period. A better solution would be to try to identify the cause of the nonhomogeneity and to include it explicitly in the system.

\section{Constraints from Utility Theory}

While the adding-up condition is of more formal nature, the homogeneity condition reflects assumptions about (individual) choice behavior. This is also true for the symmetry and negativity conditions which are based on the centerpiece of microeconomic theory, viz., utility theory. The symmetry condition, also known as the Slutsky condition, can be summarized as

$$
K=Q_{p}+q_{m} q^{\prime}=K^{\prime},
$$

where $K$ is an $n \times n$ matrix. In principle, this condition on its own provides $n(n-1) / 2$ constraints on the matrix $K$ and, hence, on $Q_{p}$ and $q_{m}$. From (2.3) it follows that

$$
p^{\prime} K=0 \text {, }
$$

which is the adding-up condition in terms of $K$. There are $n$ constraints implied by (2.10). The homogeneity condition (2.8), together with (1.2), implies that

$$
\text { (2.11) } K p=0 \text {, }
$$

giving the homogeneity condition in terms of $K$. Again there are $n$ constraints on $K$ because of (2.1). If the symmetry condition is applied in addition to the adding-up and homogeneity conditions, it generates in fact only $(n-1)(n-2) / 2$ 
constraints. For $n$ not too small this is a rather large number and the symmetry condition is in this respect a powerful one.

From (2.10) and (2.11) it is clear that the matrix $K$ is not of full rank. This is also expressed by the negativity condition

$$
y^{\prime} K y<0 \text { for all } y \neq \alpha p, \quad \alpha \text { real scalar. }
$$

An implication of this condition is that the diagonal elements of $K$ are negative, a property which can be easily checked. ${ }^{5}$

In the words of Samuelson (1947) the matrix $K$ "constitutes the most important part of the consumption theory." It is worthwhile to briefly summarize the theory on which its properties are based. ${ }^{6}$

It is assumed that the preferences of the consumer can be adequately represented by the strictly quasi-concave monotone increasing utility function

$$
u=u(q)
$$

in the $n$-real vector of quantities. This function is taken to be twice differentiable with the second-order derivatives with respect to $q$ being continuous in $q$. The vector of first-order partial derivatives of the utility function, the marginal utilities, denoted by $u_{q}$, has only positive elements (monotonicity). The matrix of second-order derivatives, $U$, is symmetric in view of Young's theorem. Strict quasi-concavity of $u(q)$ implies that

$$
x^{\prime} U x \leqslant 0 \text { for all } x \neq 0 \text { such that } U_{q^{\prime} x}=0 .
$$

Maximizing (2.13) with respect to all vectors $q$ that satisfy budget equation (1.2) yields as first-order conditions, next to (1.2),

$$
u_{q}=\lambda p
$$

where $\lambda$ is a (scalar) Lagrangean multiplier. From monotonicity it follows that $\lambda p$ is positive, or that all prices are of the same sign, say positive. Thus $\lambda$ is also positive.

The solution of (2.15) and (1.2) for $q$ and $\lambda$ in terms of $m$ and $p$ constitutes the desired set of demand equations $q=q(m, p)$ and the corresponding expression for $\lambda$. Strict quasi-concavity and monotonicity ensure the existence of such a solution. $^{7}$

To trace the consequences of the various assumptions about the utility function for the derivatives of the demand equations, differentiate both sides of (2.15) with

\footnotetext{
${ }^{5}$ As is argued by Barten and Geyskens (1975) negativity condition (2.12) might be stronger than needed in empirical demand systems. The weaker version of (2.12) would be that $K$ is a negative semidefinite matrix of, at most, rank $n-1$ and such that (2.10) and (2.11) hold.

${ }^{6}$ For a more extensive treatment see, for example, Katzner (1970).

${ }^{7}$ Order-preserving transformations of the utility function $u(q)$ do not affect the assumptions of strict quasi-concavity and monotonicity, while the first-order conditions (2.15) are only changed by a positive multiplicative scalar on both sides. The solution for the optimal $q$ is, therefore, invariant under such transformations. Assumptions about $u(q)$ that are not invariant under order-preserving transformations will not be reflected in the demand functions. Cardinality can cause no damage, but is also of no help, except perhaps for purposes of convenient exposition.
} 
respect to $m$ and $p$, resulting in

(2.16) $U q_{m}=\lambda_{m} p$,

(2.17) $U Q_{p}=p \lambda_{p}^{\prime}+\lambda I$,

respectively, where $\lambda_{m}=\partial \lambda / \partial m$ and $\lambda_{p}=\partial \lambda / \partial p$. Differentiation of (1.2) yields adding-up condition (2.3). Combining these results one has

$$
\left[\begin{array}{cc}
U & p \\
p^{\prime} & 0
\end{array}\right]\left[\begin{array}{cc}
q_{m} & Q_{p} \\
-\lambda_{m} & -\lambda_{p}^{\prime}
\end{array}\right]=\left[\begin{array}{cc}
0 & \lambda I \\
1 & -q^{\prime}
\end{array}\right]
$$

For a unique solution of the derivatives the first matrix on the left-hand side of (2.18) should be nonsingular, which requires that the weak inequality of the strict quasi-concavity condition (2.14) should be converted into a strong one-see Katzner (1968). This property is sometimes named strong quasi-concavity. ${ }^{8}$

From (2.16) and (2.3) it can be deduced that for $K=Q_{p}+q_{m} q^{\prime}$

$$
U K=\lambda\left(I-p q_{m}^{\prime}\right) \text {. }
$$

Postmultiplication of both sides of (2.19) by the symmetric matrix $U$ and use of (2.16) gives

$$
U K U=\lambda U-\lambda \lambda_{m} p p^{\prime} .
$$

The right-hand side of $(2.20)$ is symmetric, hence $K$ is also symmetric.

Premultiply both sides of (2.19) by $K$. Since $p^{\prime} K=0$-see (2.10)—and $K$ is symmetric, one has

$$
K U K=\lambda K \text {. }
$$

Hence, for $x=K y$, one has on the basis of strong quasi-concavity

$$
\lambda y^{\prime} K y=y^{\prime} K U K y=x^{\prime} U x<0,
$$

for all $x=K y \neq 0$ such that $u_{q}^{\prime} x=0$. Since $u_{q}^{\prime} x=\lambda p^{\prime} x=\lambda p^{\prime} K y$ and $p^{\prime} K=0$, $u_{q}^{\prime} x=0$ for all $y$. To have $x \neq 0$, it is required that $y$ should not be proportional to $p$. Since $\lambda$ is positive, (2.22) is equivalent with the negativity condition (2.12).

In view of the properties of the matrix $K$ it is of interest to write the system of demand equations in differential form as

$$
d q=q_{m}\left(d m-q^{\prime} d p\right)+K d p .
$$

Writing $d u=u_{q}^{\prime} d q$ and using (2.15), (2.23), (2.3), and (2.10),

$$
d u=\lambda p^{\prime} d q=\lambda p^{\prime} q_{m}\left(d m-q^{\prime} d p\right)+\lambda p^{\prime} K d p=\lambda\left(d m-q^{\prime} d p\right) .
$$

This is, in fact, the indirect utility function in differential form. The indirect utility function, $u^{*}(m, p)$, can be derived from the direct utility function $(2.13)$ by

\footnotetext{
${ }^{8}$ The property of strong quasi-concavity is also invariant under order-preserving transformations. It reflects a property of the preference ordering. Nonsingularity of the first matrix on the left-hand side of (2.18) implies that $U$ has at least rank $n-1$.
} 
replacing $q$ by $q(m, p)$. It describes the maximum attainable utility for given $m$ and $p$. The indirect utility function also plays a role in the so-called duality approach to demand analysis-see, e.g., Diewert (1974a) and Lau $(1974,1976)$, where the choice problem is formulated as finding that vector $q$ which minimizes $m=p^{\prime} q$ for a given level of utility. The result is the system

$$
q=q^{*}\left(u^{*}, p\right) .
$$

By replacing in $m=p^{\prime} q$ the right-hand side of (2.25) one then has the so-called expenditure or cost function

$$
m^{*}=p^{\prime} q^{*}\left(u^{*}, p\right)=m^{*}\left(u^{*}, p\right),
$$

giving the minimal expenditure needed to attain a given utility level for given $p$. The differential form of (2.25) follows from using (2.24) in (2.23), viz.,

$$
d q^{*}=(1 / \lambda) q_{m} d u^{*}+K d p
$$

From this expression it is clear that the term $K d p$ represents shifts in demand caused by price changes that leave the level of utility unchanged. Since Hicks (1934) and Allen (1934) it is known as the substitution effect of price changes. The matrix $K$ is, therefore, called the substitution matrix. ${ }^{9}$ The remaining price effect, namely $-q_{m} q^{\prime} d p$, is called the income effect since it can be compensated by an appropriate change in income.

Given a specification of the functional form of the direct utility function (2.13), demand functions can be obtained from the solution of the system consisting of the first-order conditions (1.2) and (2.15).

Alternatively, given a specification of the functional form of the indirect utility function, one can apply the principle of Roy (1942) to obtain the demand functions

$$
q=-\frac{\partial u^{*}(m, p) / \partial p}{\partial u^{*}(m, p) / \partial m}
$$

as can be verified immediately from (2.24). As is evident from (2.24) $\lambda=$ $\partial u^{*}(m, p) / \partial m$, or in other words, the Lagrangean multiplier $\lambda$ has the interpretation of the marginal (indirect) utility of $m$.

Still another approach is to start off from a functionally specified expenditure function (2.26). The demand functions are given by

$$
q=\partial m^{*} / \partial p=q^{*}\left(u^{*}, p\right)+K^{\prime} p=q^{*}\left(u^{*}, p\right),
$$

for a fixed value of $u^{*}$. Next, $u^{*}$ is eliminated using (2.26).

The advantage of working with such directly specified functional forms for the direct or indirect utility functions or for the expenditure function is that the resulting demand system immediately satisfies all conditions, if at least these

\footnotetext{
${ }^{9}$ The elements of the matrix $K$, the $k_{i j}$, are related to the Allen-Uzawa elasticities of substitution, $\sigma_{i j}$, by means of the definition $\sigma_{i j}=p_{i} k_{i j} p_{i} /\left(w_{i} w_{j} m\right)$ where $w_{i}$ and $w_{i}$ are the shares of expenditure on goods $i$ and $j$, respectively, in total expediture-see Hanoch (1975). Sometimes, however, the term "substitution elasticity" is used to denote $p_{i} k_{i j} p_{j} /\left(w_{i} m\right)$, which may create confusion.
} 
objective functions are properly specified, i.e., satisfy conditions about monotonicity and curvature. The disadvantage is that one loses sight of alternative and/or more general specifications.

\section{THE STRUCTURE OF THE SUBSTITUTION MATRIX}

The matrix $K$ introduced in the preceding section reflects a number of properties of the interactions among goods in the preference ordering. This can be illustrated by temporarily using the assumption that $U$, the Hessian matrix of the direct utility function, is nonsingular. It then follows from (2.19) and (2.16) that

$$
K=\lambda U^{-1}-(\lambda / \lambda m) q_{m} q_{m}^{\prime} .
$$

This result shows that $K$ can be decomposed into two components. The first one is proportional to the inverse of the Hessian matrix, while the second one is proportional to the outer vector product of the derivatives with respect to $m$. Houthakker (1960) names the latter the general substitution component and the former the specific substitution component, since it is directly related to the Hessian matrix of the utility function and, therefore, reflects information about the preference ordering. In fact, this decomposition is not invariant under order-preserving transformations of the utility function and to call the components "specific" and "general" is a matter of interpretation only. Still, if for a given utility function the Hessian matrix is, say, diagonal, the matrix $K$, itself invariant, will consist of the sum of a diagonal matrix and one which is proportional to $q_{m} q_{m}^{\prime}$.

The fact that the matrix $K$ reflects properties of the preference ordering can be used to formulate a number of constraints on it, given some prior ideas about these properties. For practical purposes this is of importance since the constraints following from the conditions of the preceding section need not be enough to control problems of multicollinearity among the prices. Some insight into the structure of $K$ can also be used to verify from a given matrix $K$ whether some meaningful structure is empirically valid.

\section{A. Utility Tree Approach}

An important source of restrictions is supplied by the separability assumptions imbedded in the utility tree approach, pioneered by Sono (1945) and Leontief (1947a, 1947b), named as such by Strotz $(1957,1959)$ and elaborated, e.g., by Gorman (1959a), Pearce (1961, 1964), Goldman and Uzawa (1964), and Blackorby et al. (1974). These authors have concentrated on properties of the utility function. Katzner (1970) has provided the link with the preference ordering.

Following Katzner, the preference ordering is separable into mutually exclusive groups of goods if the preference ordering of a certain group is independent of what one consumes of the goods outside the group. Then, two levels in the decision process can be distinguished. On the first level it is being decided what to spend on each group in total. On the second level the actual choice of the quantities of the goods in each group is made, given the total expenditure for the 
group. This second level allocation problem is formally analogous to the overall choice problem. In other words, for each group, there exists a set of demand functions like (1.1), with only expenditure on the group and the prices for the goods of that group as arguments. Let $q_{F}$ be the vector of quantities of goods belonging to group $F(F=1, \ldots, N), p_{F}$ the corresponding prices and $m_{F}=p_{F}^{\prime} q_{F}$; one then has

$$
q_{F}=q_{F}\left(m_{F}, p_{F}\right) \text {. }
$$

Prices of goods of other groups can only affect demand for $q_{F}$ by way of their impact on $m_{F}$. This implies a possibly important number of constraints on the matrix $K$. This can be shown as follows.

Let $F \neq G$ and let $K_{F G}$ be the submatrix of $K$ associated with the substitution effect of $p_{G}$ on $q_{F}$. From (3.2) it follows that

$$
\partial q_{F} / \partial p_{G}^{\prime}=q_{e F} \partial m_{F} / \partial p_{G}^{\prime},
$$

where $q_{e F}=\partial q_{F} / \partial m_{F}$. From earlier results one has

$$
\partial q_{F} / \partial p_{G}^{\prime}=-q_{m F} q_{G}^{\prime}+K_{F G}
$$

where $q_{m F}=\partial q_{F} / \partial m$. Note that $q_{m F}$ is proportional to $q_{e F}$, since $q_{m F}=$ $q_{e F}\left(\partial m_{F} / \partial m\right)$. Combining (3.3) and (3.4) one obtains

$$
K_{F G}=q_{e F}\left[\partial m_{F} / \partial p_{G}^{\prime}+\left(\partial m_{F} / \partial m\right) q_{G}^{\prime}\right] \text {. }
$$

In view of the symmetry of $K, K_{F G}=K_{G F}^{\prime}$. Consequently, one can write

$$
K_{F G}=-\psi_{F G} q_{e F} q_{e G}^{\prime}=K_{G F}^{\prime},
$$

where $\psi_{F G}$ is a (scalar) factor of proportionality. In an analogous way one can show that

$$
K_{F F}=K_{F}-\psi_{F F} q_{e F} q_{e F}^{\prime},
$$

where $K_{F}$ is the substitution matrix associated with subsystem (3.2). ${ }^{10}$

For applications the separability assumption has a number of interesting consequences. First of all, one can concentrate one's attention on a single subsystem, like (3.2), taking the explanation of $m_{F}$ to follow from another line of research. For example, one may group the commodities according to the period of their consumption. If the preference ordering is separable in those groups, there exists a subsystem for each period. The question of what to spend on consumption is to be answered by the theory of the consumption function, where intertemporal elements and expectations play a role. How this amount is allocated over the goods in the period under study is a question to be answered by the theory of consumer demand functions, where one can thus ignore intertemporal aspects. ${ }^{11}$

${ }^{10}$ One can write (3.7) also as $K_{F}=K_{F F}+\psi_{F F} q_{e F} q_{e F}^{\prime}$. Note the formal analogy with (3.1). Note that (3.7) is invariant under order-preserving transformations of the utility functions and that $K_{F F}$ will usually have full rank.

${ }^{11}$ Although the complete set approach is usually applied to one-period allocation problems, nothing prevents its application to the allocation of resources over many periods. Diewert (1974b), for example, applies the general Leontief system to a multiperiod decision problem to describe consumption per year, the use of financial means and of time for work and leisure. 
This decomposition makes it possible to concentrate on one issue at a time. Secondly, under separability, the problem of aggregation over commodities finds a natural solution. It follows from the differential form of the full system (2.23) that for a particular group

$$
d q_{F}=q_{m F}\left(d m-q^{\prime} d p\right)+\sum_{G} K_{F G} d p_{G} .
$$

Note that $p_{F}^{\prime} d q_{F}$ is the change in expenditure on group $F$ due to a change in the quantities of the goods of group $F$ and that $p_{F}^{\prime} q_{m F}=b_{F}$ is the marginal propensity to spend on items of this group. Use of (3.6), (3.7), and the property that $p_{F}^{\prime} q_{e F}=1$, yields

$$
p_{F}^{\prime} d q_{F}=b_{F}\left(d m-q^{\prime} d p\right)+\sum_{G} \chi_{F G} d \pi_{G}
$$

where $d \pi_{G}=q_{e G}^{\prime} d p_{G}, \chi_{F G}=\psi_{F G}$ for $F \neq G$, and $\chi_{F F}=-\Sigma_{G \neq F} \chi_{F G}$. Here $d \pi_{G}$ can be considered as the change in a group index number, to be distinguished from $q_{G}^{\prime} d p_{G}$ which is the group index number associated with the income effect in the first term on the right-hand side of (3.9). For practical purposes, using $q_{G}^{\prime} d p_{G}$ for $d \pi_{G}$ need not have an important effect-see, e.g., Barten and Turnovsky (1966). Note that the $N \times N$ matrix of $\chi_{F G}$ reflects all the conditions formulated for $K$ in the preceding section. It is symmetric, its columns and rows add up to zero (adding-up and homogeneity), and it satisfies a negativity condition. This means that (3.9) can be considered as an equation of a complete set of demand equations for aggregate commodities. This result justifies the application of the complete set approach to commodity aggregates, which is empirically usually unavoidable.

When estimating full systems, clearly relations like (3.6) can be implicitly or explicitly used. This happens implicitly if one starts off from a specified utility function which is separable in the groups of goods, like in general terms

$$
u=\tilde{u}\left(u_{A}\left(q_{A}\right), u_{B}\left(q_{B}\right), \ldots, u_{N}\left(q_{N}\right)\right)
$$

with $u_{F}\left(q_{F}\right)$ being a "partial" utility function. It is possible that these partial utility functions are further separable in subgroups and so on. Such a structure has been named a utility tree. The general case is that of weak separability. Strong separability occurs when $u$ can be transformed into a utility function which is additively separable in the partial utility functions. A limit case is the one where the utility function is strongly separable in the elementary commodities. Many applications have started off from such utility functions. Under strong separability (3.6) becomes $(F \neq G)$

$$
K_{F G}=-\psi^{*} q_{m F} q_{m G}^{\prime}
$$

where $\psi^{*}$ is independent of the pair of groups of goods involved. A special case is the one of Pearce separability, or want neutrality. Then the utility function is separable in groups but the partial utility functions are strongly separable in the elementary goods. 


\section{B. Other Approaches}

Separability assumptions have been used over and over again, but their usefulness depends on the ability to classify goods into groups for which the separability assumption may be considered empirically valid. It is therefore useful to consider some other approaches to structure the preference ordering and, hence, the substitution matrix where separability in mutually exclusive groups of market goods is not assumed or implied.

The Lancaster (1966) approach starts off from a utility function in terms of $m$ basic characteristics, say, $x$, to which the goods in the usual sense are related by $q=A x$. The elements of the matrix $A$ can be interpreted as input requirements to produce a unit of $x$. The substitution matrix $K$ of the system for $q$ can then be written as $A K_{x} A^{\prime}$, where $K_{x}$ is the corresponding concept for the demand equations for basic characteristics. Restrictions on $K$ follow from assumptions made about the separability of the utility function in the basic characteristics and about $A$.

The approach of Theil (1971b) is similar to that of Lancaster in the sense that he uses a nonsingular transformation $x=C^{\prime} q$ such that the utility function is strongly separable in $x$. In fact, $C$ is defined by $U=C C^{\prime}$. From (3.1) it can be seen that then $K=\lambda C^{\prime-1} C^{-1}-\left(\lambda / \lambda_{m}\right) q_{m} q_{m}^{\prime}$. No specific restrictions on $K$ follow from this approach but, given an estimate of $K$, one can construct overlapping groupings, which give an insight into the technology of preferences.

Also, Gorman (1959b, 1973) has developed an approach to analyze the structure of tastes from actual demand data. He searches for the basic characteristics that determine the preferences for certain groups of goods. In Gorman (1959b) demand for various types of fish is analyzed in this way.

The work of Becker (1965) is, in a sense, formally related to these approaches. He starts off from a utility function in terms of directly consumable goods and in leisure time. These are related to market goods and household time by way of household production functions. With a suitable definition of $m$, this approach yields, in addition to demand functions for market goods, a supply function for labor. Information about the household technology can be used to formulate constraints on $K$.

Although these alternative approaches are somewhat outside the current mainstream of the empirical work on demand systems, they have an interesting feature. They make it somewhat easier to introduce new goods into the analysis, since a new good can be considered as another way to produce "satisfaction" of the existing set of basic characteristics or needs. If one knows how the new good is related to the basic characteristics, one can immediately derive its demand equation. As yet the treatment of new goods or quality changes has not been undertaken in the context of demand systems.

\section{AGGREGATE DEMAND}

The theoretical basis of systems of demand functions is mostly the theory of the individual agent. The data used for empirical applications usually refer to demand 
for consumer goods in a whole economy. To what extent can micro theory and, more specifically, the constraints it implies for the demand equations, be considered relevant for the description of aggregate demand behavior?

Apart from considering demand and expenditure per capita, most of the empirical contributions have simply ignored this question. However, aggregation clearly provides some problems as will be now demonstrated. Let the subscript $h$ $(1, \ldots, H)$ indicate that the concept $i$ in question refers to individual behavior, while the absence of the subscript indicates the corresponding average. By definition, one has

$$
q=(1 / H) \sum_{h} q_{h}, \quad m=(1 / H) \sum_{h} m_{h}=(1 / H) \sum_{h} p^{\prime} q_{h}=p^{\prime} q .
$$

The prices $(p)$ are considered equal for all individuals. Micro theory is relevant for the system

$$
q_{h}=q_{h}\left(m_{h}, p\right),
$$

while for empirical work one is interested in

$$
q=q(m, p)
$$

From (4.1) and (4.2) one has, however,

$$
q=(1 / H) \sum_{h} q_{h}\left(m_{h}, p\right) .
$$

Obviously, (4.3) and (4.4) are only equivalent under rather restrictive assumptions about the variations in $m_{h}$ and $q_{h}($ ) across individuals.

The problem can also be formulated in terms of the differential forms of the respective systems. Corresponding with (4.3) one has

$$
d q=q_{m} d m+Q_{P} d_{p}
$$

while for (4.4)

$$
d q=(1 / H) \sum_{h} q_{m h}\left(d m_{h}-q_{h}^{\prime} d p\right)+K d p,
$$

where $K=(1 / H) \Sigma_{h} K_{h}$. Note that $K$ shares all the properties of $K_{h}$ put forward in the second section of this review, but not those like (3.6) or (3.1) given in the third section.

There would be no problem at all if $q_{m h}=q_{m}$ for all $h$. Then (4.5) and (4.6) are equivalent, with $Q_{p}=K-q_{m} q^{\prime}$ and all the micro conditions from both preceding sections can be carried over to the macro level. This condition is, however, only slightly weaker than the assumption of the "representative consumer"-see Frisch (1959) - which is tantamount to the assumption that all consumers are identical. For empirical purposes, conditions for exact aggregation are less interesting than those for consistent aggregation, which is achieved when, in the limit, for $H \rightarrow \infty$, the properties of the macro relation are equivalent to those of the corresponding micro relation. For consistent aggregation it is sufficient that 
certain empirical covariance matrices tend to zero-see, e.g., Theil (1975a) and Barten (1974).

Other avenues are open to reconcile micro theory with its macro applications. One would be to formulate distribution functions for micro characteristics such that the macro relations display the desired properties. Another one would be to introduce explicitly distributional characteristics in the demand equations. These approaches have hardly been explored. ${ }^{12}$

In the present state of the art the problems posed by aggregation remain mainly unsolved. Still, it would be unwarranted to attribute rejections in the case of tests of micro conditions in the context of macro systems only to the aggregation issue. They could be due to inadequate data, functional specification errors, incorrect treatment of random components, and so on. The empirical importance of possible distortions caused by aggregation errors is largely unknown. They could very well be of less importance than other imperfections. Moreover, the alternative to resort to purely empirical demand studies is also not without problems. How does one handle the problem of aggregation over commodities without some (micro) theoretical reasoning? How should one control the problem of multicollinearity among the prices? If one has to use some constraints why not those that have a (micro) theoretical basis?

\section{RELATED ISSUES}

Most of the microeconomic theory underlying demand systems is concerned with the changes in equilibrium positions caused by changes in $m$ and $p$. Actual demand behavior observed over fixed and limited periods over time also undoubtedly reflects changes in other determinants, while imperfections in the adjustment process also play a role. There are many possibilities for increasing the realism of the model. In this section only a few of these will be discussed.

\section{A. The Impact of Other Determinants}

Let $x$ be a $k$-vector of "other" determinants, i.e., factors other than $m$ and $p$ that cause shifts in the demand vector $q$. Assuming that the demand functions are differentiable with respect to $x$, the matrix $Q_{x}$ will be used to denote the matrix of derivatives of $q$ with respect to $x$. Since by definition, $x$ will not affect $m$ and $p$, differentiation of both sides of $p^{\prime} q=m$ results in the adding-up condition

$$
p^{\prime} Q_{x}=0 .
$$

In other words, a shift in the demand for one good has to be compensated by a shift in the other direction in the demand for other goods.

From a theoretical point of view, changes in $x$ are only of interest insofar as they affect the first-order condition $u_{q}=\lambda p$. Differentiation of the condition with respect to $x$ yields

$$
U Q_{x}+U_{q x}=p \lambda_{x}^{\prime}
$$

\footnotetext{
${ }^{12}$ Recently, Muellbauer (1975) has tried to tackle this issue, while Berndt, et al. (1976), working in the same spirit as Muellbauer's, have included effects of changing income distributions in their application of various demand systems to Canadian data for 1959-1971.
} 
where $U_{q x}=\partial u_{q} / \partial x^{\prime}$ and $\lambda_{x}=\partial \lambda / \partial x$. Premultiply both sides of (5.3) by $K=K^{\prime}$ and use (2.19), (2.10), and (5.1) to obtain

$$
Q_{x}=-(1 / \lambda) K U_{q x} \text {. }
$$

This shows how the effect of "other" determinants is related to the substitution effect of price changes.

In many applications a time trend is introduced to absorb all types of timedependent shift factors. This practice already goes back to the first application of the linear expenditure system by Stone (1954). One can give such a time trend the interpretation of a trendlike change in preferences. Its effect on $q$ must obey (5.1). Only if one specifies how the marginal utilities are changed by such a trend will (5.3) be useful as a source of constraints.

\section{B. Dynamics}

It is realistic to assume that past behavior will change preferences and consequently affect current behavior. In the context of the linear expenditure system, Pollak and Wales (1969) introduced a fairly simple specification of how demand in the previous period changes the utility function and the resulting demand functions.

A more refined approach was opened up by Houthakker and Taylor (1965). They make preferences dependent on stocks, which can be of the usual physical type or of a more psychological variety (habits). Since physical stocks are usually and habits nearly always unobservable, they do not appear explicitly in the demand functions. The effect of their changes is instead represented by lagged demand, income, and prices. The approach of Houthakker and Taylor has led to a number of interesting applications by others also. ${ }^{13}$ The empirical complications introduced by endogenously changing preferences has, until now, forced most researchers to confine their attention to the case of strongly separable (or additive) preferences. Undoubtedly, future research will try to apply dynamics to more general preference structures. ${ }^{14}$

\section{Random Shifts}

Disturbances are usually tacked on to demand equations as a kind of afterthought. As far as they find their origin in random shifts in preferences their effects on demand can be related to those of price changes, as was already pointed out by Allen and Bowley (1935). This relation has been first made explicit by Theil and Neudecker (1957). It has been further exploited by Theil (1971a, 1971b, 1975a, 1975b) for the specification of the covariance matrix of the disturbance terms of the demand equations. He specifies it to be negatively proportional to $K$, which, if realistic, has interesting consequences for estimation (see, e.g., Barten (1968)).

\footnotetext{
${ }^{13}$ See, e.g., Lee (1970), Phlips (1972, 1974), Taylor and Weiserbs (1972), and Rossier (1974).

${ }^{14}$ Lluch (1974) discusses a system where habit formation is introduced in a general quadratic utility function. At present, no empirical results are available.
} 
Not only is more information then mobilized to estimate $K$ given a fixed sample size, but it also makes it possible to use full information methods to estimate the system when the time series would not be long enough to allow an unconstrained estimation of the covariance matrix. On a more inductive level, Phlips (1971) and Phlips and Rouzier (1972) have analyzed empirical covariance structures to obtain further information about the interactions between goods.

It should be realized that randomly changing preferences are only one source of error terms in the demand equations. All possible imperfections in the approach will be reflected in these error terms and are not easy to isolate. However, some theory is better than a complete agnostic attitude.

\section{FUNCTIONAL FORM}

In principle, there is an infinite variety of possible functional forms for demand equations. It would be beyond the limited scope of this review to survey all actually used specifications. Even for the ones explicitly discussed here no attempt will be made to quote all of the published applications.

In practice, three different approaches to functional form specification are used. The first one starts off from a functionally specified direct utility function. The second one is based on a specified functional form for the indirect utility function. ${ }^{15}$ These two approaches have the advantage that the resulting demand equations display, more or less automatically, all properties discussed in the second and third sections. The third approach specifies the functional form of the demand equations directly and imposes next the conditions in question. A few examples from each approach will be presented here.

\section{A. Specified Direct Utility Functions}

Most of the actually used variants of the approach taking off from functionally specified direct utility functions let these functions be strongly separable in the elementary goods or groups of goods. Johansen (1969) formulated a general additive utility function, which implies several of the proposed demand functions as special cases. ${ }^{16}$ The Johansen function is as follows:

$$
u=\sum_{i} \frac{\beta_{i}}{\alpha_{i}}\left(\frac{q_{i}-\gamma_{i}}{\beta_{i}}\right)^{\alpha_{i}}
$$

\footnotetext{
${ }^{15}$ Actually, one can also take a functional specification of the expenditure function (2.26) as one's starting point. This is done by Diewert (1974a, 1974b), and Muellbauer (1975). In view of the one-to-one relation between the expenditure function and the indirect utility function this approach is not treated separately.

${ }^{16}$ The Johansen function (6.1) can be extended by the addition of a quadratic term, namely

$$
u=\sum_{i} \frac{\beta_{i}}{\alpha_{i}}\left(\frac{q_{i}-\gamma_{i}}{\beta_{i}}\right)^{\alpha_{i}}+\frac{1}{2} \sum_{i} \sum_{j} \beta_{i j} \frac{\zeta_{i} \zeta_{j}}{\delta_{i} \delta_{j}}\left(\frac{q_{i}-\varepsilon_{i}}{\zeta_{i}}\right)^{\delta_{i}}\left(\frac{q_{j}-\varepsilon_{j}}{\zeta_{j}}\right)^{\delta_{j}}
$$

where if $\alpha_{i}=0$ and/or $\delta_{i}=0$, one replaces the relevant terms by their limits for $\alpha_{i} \rightarrow 0$ and $\delta_{i} \rightarrow 0$, respectively. The direct translog utility of Christensen, et al. (1975) is a special case of the utility function above, namely for $\alpha_{i}=\delta_{i}=\gamma_{i}=\varepsilon_{i}=0$ for all $i$ since it can be written as

$$
u=\text { constant }+\sum_{i} \beta_{i} \ln q_{i}+\frac{1}{2} \sum_{i} \sum_{j} \beta_{i j} \ln q_{i} \ln q_{i j}
$$
}


where $\alpha_{i}<1, \beta_{i}>0$, and $\gamma_{i}<q_{i}$ are constants. If $\alpha_{i}=0$ the relevant term in (6.1) is replaced by its limit for $\alpha_{i} \rightarrow 0$, namely

$$
\beta_{i} \ln \left(q_{i}-\gamma_{i}\right)-\beta_{i} \ln \beta_{\mathrm{i}}{ }^{17}
$$

From the first-order condition (2.3) one obtains

$$
q_{i}=\gamma_{i}+\beta_{i}\left(\lambda p_{i}\right)^{1 /\left(\alpha_{i}-1\right)},
$$

from which $\lambda$ has to be eliminated. The use of the budget equation does not yield elegant analytical results. For estimation purposes one could select one particular good, say the $n$th one, to eliminate $\lambda$ from (6.3) viz.,

$$
q_{i}=\gamma_{i}+\beta_{i}\left[\left(\frac{q_{n}-\gamma_{n}}{\beta_{n}}\right)^{\alpha_{n}-1} \frac{p_{i}}{p_{n}}\right]^{1 /\left(\alpha_{i}-1\right)} \quad(i=1, \ldots, n-1) .
$$

TABLE I

Additive Demand System, Derived fRom (6.1)

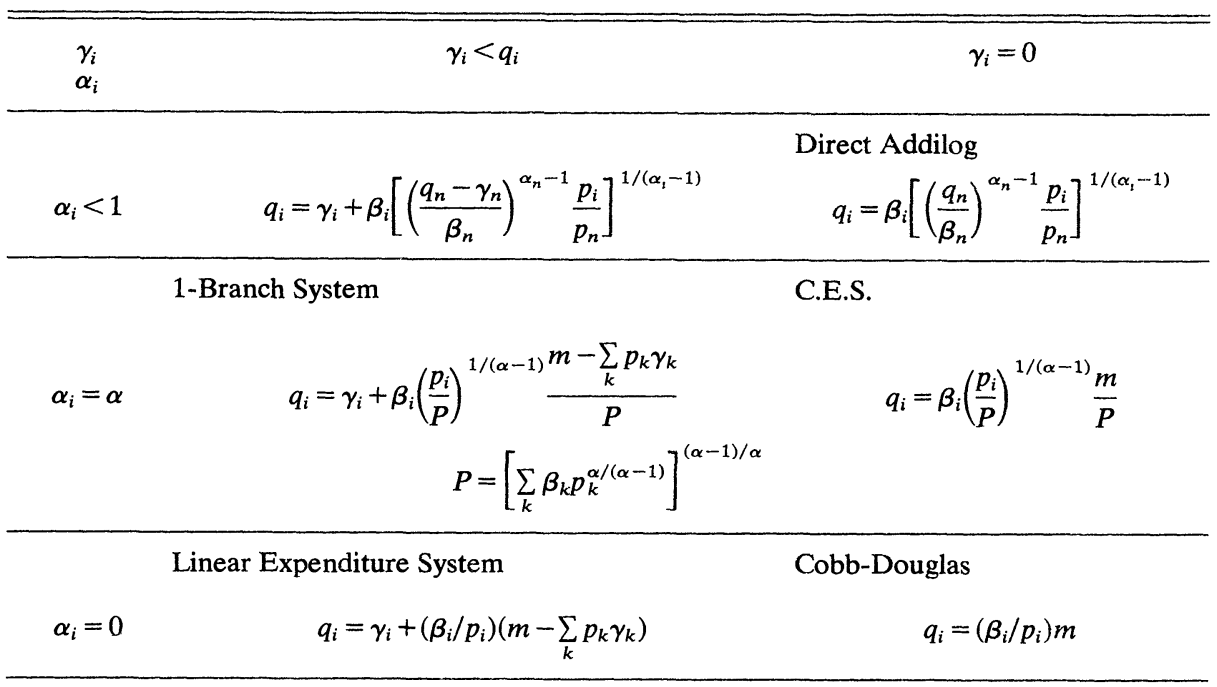

This system has never been utilized as such in applications. Elimination of $\lambda$ by means of the budget equation is easier when $\alpha_{i}=\alpha$ for all $i$. In Table I the various alternatives are brought together. On the right-hand side of this table one finds the specifications for $\gamma_{i}=0$. The direct addilog system was first proposed by Houthak$\operatorname{ker}(1960)$. When $\alpha_{i}=\alpha$ it reduces to the C.E.S. case, so named because then $u^{1 / \alpha}$ is formally equivalent to the constant elasticity of substitution production function. Houthakker (1965) calls it the "self-dual addilog system" because the

${ }^{17}$ If $\alpha_{i}=0$ for all $i$, the utility function can be written as $u=\Sigma_{i} \beta_{i} \ln \left(q_{i}-\gamma_{i}\right)$, which is known as the Stone-Geary utility function. 
indirect utility function is of the same functional form as (6.1). The income elasticity is unity for all goods in the C.E.S. system. A fortiori, it is so in the Cobb-Douglas system where the budget shares $w_{i}=p_{i} q_{i} / m=\beta_{i}$ are constant. In general, if $\alpha_{i}=\alpha$, the derivatives with respect to $m$ are independent of $m$, i.e., one has linear Engel curves even if the $\gamma_{i} \neq 0$. For $\gamma_{i} \neq 0$, but $\alpha_{i}=\alpha$, one has the 1-branch system, since it is the system which results from the $S$-branch utility tree of Brown and Heien (1972) by putting $S=1$. A special case is the linear expenditure system (L.E.S.), so named because $p_{i} q_{i}$ is linear in $m$ and $p$. The L.E.S. is one of the most widely used systems. It was first applied by Stone (1954). For a detailed discussion reference is made to Deaton (1975).

In this connection it is convenient to mention that one can extend the Johansen function quite easily to deal with strong separability in groups by writing

$$
u=\sum_{F} \frac{\beta_{F}}{\alpha_{F}}\left(\frac{u_{F}\left(q_{F}\right)-\gamma_{F}}{\beta_{F}}\right)^{\alpha_{F}}
$$

where $u_{F}$ is defined by (6.1) with $i$ referring to goods of group $F$ only. The $S$-branch system of Brown and Heien (1972) already mentioned uses the C.E.S. variant of (6.5) and for the $u_{F}\left(q_{F}\right)$ the Johansen function (6.1) with $\alpha_{i}=\alpha_{F}^{\prime}$. The combination of (6.5) with (6.1) for the partial utility functions is actually an example of strong Pearce-separability: strong separability in groups and within groups in goods. Note that this does not imply overall strong separability.

Returning again to (6.1), it can be observed that there are at most $3 n$ parameters to estimate in this system. In case $\alpha_{i}=\alpha$ this number is reduced to $2 n$, since then the $\beta_{i}$ can only be identified up to a factor of proportionality which may be chosen arbitrarily. For this economy of parameters one has to pay a price. Let $\varepsilon_{i j}=\partial \ln q_{i} / \partial \ln p_{j}$ and $\eta_{i}=\partial \ln q_{i} / \partial \ln m$ be the price elasticities and the income elasticities of demand, respectively. Then, as shown for example by Frisch (1959),

$$
\varepsilon_{i j}=\delta_{i j} \phi \eta_{i}+\eta_{i} w_{j}\left(1-\phi \eta_{j}\right),
$$

where $\delta_{i j}$ is the Kronecker delta, $1 / \phi=\partial \ln \lambda / \partial \ln m$, and $w_{j}=p_{j} q_{j} / m$ is the average budget share. The first term will dominate the second term when $w_{j}$ is small, which one may expect if one works with already a moderate number of goods. Hence $\varepsilon_{i i} \sim \phi \eta_{i}$ which Deaton (1974b) calls Pigou's Law since it was put forward by Pigou (1910). The proportionality of the direct price elasticity and the income elasticity of a good is too restrictive to the taste of an empirical demand analyst. Indeed, under additive or strongly separable preferences, the cross specific substitution effects are, by definition, zero while, empirically, the general substitution effect together with the income effect is negligible. One is left with only the direct specific substitution effect. The structure (6.1) imposed on the interactions between demand for commodities is so restrictive that it frustrates one of the main purposes of the construction of empirical demand systems, namely a coherent and empirically valid measurement of those interactions. By suppressing the interactions, one remains coherent, but the empirical validity might be reduced to an unacceptably low level. Strong Pearce-separability allows for more flexibility but the fact that the partial utility functions are additive implies 
that within the groups, where one would expect nontrivial interactions again, these are not allowed to show up. ${ }^{18}$

\section{B. Specified Indirect Utility Functions}

To derive a class of demand systems based on specified indirect utility functions one can also start from a general expression for the indirect utility function, ${ }^{19}$ namely

$$
u^{*}=\sum_{i} \frac{\beta_{i}\left(\alpha_{i}-1\right)}{\alpha_{i}}\left(z_{i}-\rho_{i}\right)^{\alpha_{i} /\left(\alpha_{i}-1\right)},
$$

where $z_{i}=p_{i} /\left(m-m_{0}\right)$, with $m_{0}=\left(\Sigma_{k} \gamma_{k} p_{k}^{\nu}\right)^{1 / \nu}<m$, and $\alpha_{i}<1, \beta_{i}>0, \rho_{i}<z_{i}$, and $\gamma_{i}$ are constants. If $\alpha_{i}=0$, the relevant term in (6.7) is replaced by its limit for $\alpha_{i} \rightarrow 0$, namely $\beta_{i} \ln \left(z_{i}-\rho_{i}\right)$. Using Roy's rule (2.13) the resulting demand equations are the following:

$$
q_{i}=\gamma_{i}\left(\frac{m_{o}}{p_{i}}\right)^{1-\nu}+\frac{\beta_{i}\left(z_{i}-\rho_{i}\right)^{1 /\left(\alpha_{i}-1\right)}}{\sum_{k} \beta_{k}\left(z_{k}-\rho_{k}\right)^{1 /\left(\alpha_{k}-1\right)} p_{k}}\left(m-m_{o}\right) .
$$

Expression (6.7) reduces to the indirect addilog specification of Houthakker (1960) for $\rho_{i}=0$ and $\gamma_{i}=0$, implying $m_{0}=0$. Then (6.8) becomes

$$
q_{i}=\beta_{i}\left(p_{i} / m\right)^{1 /\left(\alpha_{i}-1\right)} / \sum_{k} \beta_{k}\left(p_{k} / m\right)^{\alpha_{k} /\left(\alpha_{k}-1\right)} \text {. }
$$

This system was proposed for the first time by Leser (1941) and has been extensively used by Somermeyer, et al. $(1956,1962,1972,1973)$. Note that in (6.8) the $\beta_{i}$ are only identifiable up to a constant of proportionality, which one may select such that $\Sigma_{i} \beta_{i}=1$. For $\alpha_{i}=\alpha$ one obtains the C.E.S. demand functions, introduced above, with the Cobb-Douglas as the special case corresponding to $\alpha=0$. The general form (6.8) looks like a generalization of the 1-branch system (see Table I). Indeed, when $\rho_{i}=0, \nu=1$, and $\alpha_{i}=\alpha$, it emerges, and for $\alpha_{i}=0$ one has the L.E.S. demand equations. However, for $\nu \neq 1$ one has a generalization of both these systems, amounting to replacing the $\gamma_{i}$ by $\gamma_{i}\left(m_{0} / p_{i}\right)^{1-\nu}$.

Specification (6.8) involves $4 n$ parameters. Although this yields some flexibility, it is to be noted that prices of other goods enter the demand equations only in the form of indices and deflators. Specific interactions have again not much chance to show up. Pollak (1972) calls this property "generalized additive separability."

${ }^{18}$ The application of the concept of implicit additivity as put forward by Hanoch (1975) provides one way to avoid Pigou's Law without having to estimate an overly large number of parameters. Still, a substantial amount of a priori structuring of substitution effects is involved, limiting the application of this approach to broad aggregates.

${ }_{19}$ Also, (6.7) can be extended to include quadratic terms. A special case would then be the indirect translog utility function of Christensen, et al. (1975) which can be written as

$$
u^{*}=\text { constant }+\sum_{i} \beta_{i} \ln \left(p_{i} / m\right)+\sum_{j} \sum_{j} \beta_{i j} \ln \left(p_{i} / m\right) \cdot \ln \left(\mathrm{p}_{\mathrm{j}} / \mathrm{m}\right) .
$$

Another one is the system used by Diewert (1974b) which can be derived from

$$
u^{*}=\sum_{i} \sum_{j} \beta_{i j}\left(p_{i} / m\right)^{\frac{1}{2}}\left(p_{j} / m\right)^{\frac{1}{2}} \text {. }
$$




\section{Directly Specified Demand Functions}

Generalized additive separability is also the property of the demand functions of Fourgeaud and Nataf (1959):

$$
q_{i}=q_{i}\left(\frac{m}{P}, \frac{p_{i}}{P}\right)
$$

where $P$ is a function of the prices that is homogeneous of degree one. By employing the adding-up and symmetry conditions Fourgeaud and Nataf derive four types of demand equations. Their work has served as the basis for the empirical applications by Nasse (1973). Some of the systems mentioned before are clearly of the type (6.10) like the C.E.S. system and the L.E.S. with $P=$ $\Sigma_{k} p_{k} \gamma_{k}$. The strong point of the Fourgeaud-Nataf approach is the flexibility it allows for introducing the influence of total expenditure $m$, its weak point being the constraint imposed on the price effects.

Other specifications have been used that do not build in such limited interaction from the beginning. However, the use of the various conditions tends to narrow down interactions. One well-known case is that in which one expresses the expenditure on a good as a linear function of total expenditure and all the prices. As was shown by Klein and Rubin (1949), the result of the use of homogeneity, adding-up and symmetry conditions is the L.E.S., which displays strong separability. However, by imposing symmetry only at the mid-point of the sample, as was done by Leser $(1958,1960,1961)$ and by Powell $(1966,1974)$ one can maintain linear expenditure functions with full scope for interactions.

More or less the same story can be told about the log-linear demand equations. It is not difficult to show that imposing the classical set of conditions for all possible $(m, p)$ combinations results in the Cobb-Douglas case. When imposing the restrictions only for the sample average, as was done, e.g., by Barten (1964) and Byron (1970), one can allow for full interactions. However, as pointed out by Sato (1972), the log-linear demand equations in terms of deflated total expenditure and the relative own price only, could very well be good empirical approximations to the ones of the direct addilog system. This is some comfort to the more applied demand analysts who have always favored such simple log-linear demand equations.

Theil (1965) proposed a variant of the log-linear specification which has subsequently become known as the "Rotterdam system". There the dependent variables are $\bar{w}_{i t} \Delta \ln q_{i t}$, where $\bar{w}_{i t}=\left(w_{i t}+w_{i t-1}\right) / 2$. The constants are the elasticities multiplied by these $\bar{w}_{i t}$. All the usual restrictions plus those following from separability can be easily expressed in terms of the parameters of the system. ${ }^{20}$ However, as has been pointed out by McFadden (1964) and by Goldberger (1969), the ultimate implication of this parametrization is the Cobb-Douglas system.

\footnotetext{
${ }^{20}$ For empirical application of the Rotterdam system see, e.g., Theil (1967, 1971b, 1975a), Barten (1967, 1968, 1969, 1974), Barten and Turnovsky (1966), Vinci (1967), Salvas-Bronsard, et al. (1973), and Barten and Geyskens (1975).
} 


\section{Further Considerations}

The systems considered in this section either have limited interaction built in from the start, due to the relatively simple structure of the direct and indirect utility functions on which they are based, or have it implied by the choice of the structural form, even though a full unstructured substitution matrix is or can be estimated. This appears to be an unsatisfactory situation.

There are several ways to approach this issue of rigidity of demand systems. One is to relax it in a partial way. For example, Deaton (1974c) makes the $\gamma_{i}$ of the 1-branch system a function of relative prices. It still implies a considerable degree of structuring of price responses. Another example is the implicit direct and indirect additivity models of Hanoch (1975). In the direct variant the ratios of the cross elasticities of substitution are kept constant (CRES), i.e., $\sigma_{i j}=g(m, p) \varepsilon_{i} \varepsilon_{j}$ $(i \neq j)$, where the $\varepsilon$ 's are constants. In the direct variant the differences in the cross elasticities of substitution are constants (CDE), implying $\sigma_{i j}=\zeta_{i}+\zeta_{j}+h(m, p)$ $(i \neq j)$, with constant $\zeta$ 's. In view of the simple relation between the $k_{i j}$ and $\sigma_{i j}$ (see footnote 9), such specifications amount again to a limitation of interactions. The Deaton and Hanoch approaches are both generalizations or more rigid formulations. They will lead to an improvement of empirical performance, but will fail to capture specific relations between various goods.

Such interactions have much more chance to show up in the general Leontief expenditure system of Diewert (1974b) and in the transcendental logarithmic utility systems of Christensen, et al. (1975) ${ }^{21}$ Both approaches are based on utility functions which are special cases of quadratic extensions of (6.1) and (6.7). Working with richer utility functions undoubtedly offers advantages in better representation of interactions; but one quickly runs into systems of demand equations which are difficult to estimate because they are highly nonlinear in the parameters. In principle, modern computer facilities can deal with such estimation problems. Still, actual applications by Diewert (1974b) and Christensen, et al. (1975) have been limited to systems for only three types of goods. This is unfortunate since the possibility to capture specific interaction is in particular of interest for systems with a more detailed breakdown in groups of goods.

One can also look at the issue of too limited interaction from another angle. Systems like the log-linear and the Rotterdam ones which have no restrictive structuring of the estimating equations imply restricted interactions because of the choice of the functional form, i.e., because the coefficients to be estimated are taken to be constants. However, the constant nature of these coefficients should not be taken too seriously. A "constant" in applied econometrics is a magnitude which varies less than the variables it links. The merest deviation from constancy, although empirically hardly measurable, may remove the restrictions on the interactions.

\footnotetext{
${ }^{21}$ As is evident from footnotes 16 and 19 , such specific interactions are "coded" by the nonzero $\beta_{i}$ $(i \neq j)$ in the underlying utility functions.
} 


\section{EMPIRICAL PERFORMANCE}

In general, the estimated versions of demand systems have relatively large residuals. This is not always reflected in the coefficients of determination of the equations which have the levels of demand or expenditure as the dependent variable. Whenever one takes first differences the $R^{2}$ 's are relatively low. Apparently not all the variations in observed demand can be explained by the variations in income and prices only. One should view the demand systems approach more as an attempt to describe the impact of changes in income (or total expenditure) and prices than as one to explain changes in demand exhaustively.

In the case of nondynamic demand equations with the levels of demand or expenditures as the dependent variables the residuals usually display a high degree of positive autocorrelation. Berndt and Savin (1975) present a method to deal with this feature, which is usually ignored. Taking first differences removes most of the autocorrelation, but is actually only a special case of the Berndt-Savin procedure.

In most, more sophisticated, estimations of demand systems one works with nondiagonal contemporaneous covariance matrices for the disturbance terms. Usually intertemporal homoscedasticity is assumed. As far as is known to the present author, the use of intertemporal heteroscedasticity has not been investigated at length. It is quite evident that when estimating the L.E.S. for a long period the fact that the dependent variables are expenditures in current prices might introduce such heteroscedasticity as a function of the general price level. Using the average budget shares for the goods as dependent variables might be one way to deal with this issue, but other schemes are worth investigating.

\section{A. Empirical Comparison of Functional Forms}

Some authors have attempted to compare the empirical performance of different functional form specifications. Parks (1969) used the average information inaccuracy measure-see Theil (1967) - to compare the performance of the Rotterdam system, the indirect addilog system, and the linear expenditure system, with and without linear trends in the $\beta_{i}$ 's and $\gamma_{i}$ 's, and also a naïve model implying no changes from year to year. The data used refer to demand for consumer goods for eight industries in Sweden, 1862-1955. It turns out that the Rotterdam model dominates the others substantially. The indirect addilog is slightly better than the L.E.S., where the introduction of trends does not change the picture drastically and which is sometimes even inferior to the naive model. The same picture

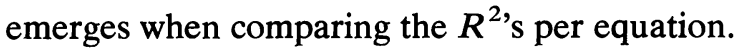

Deaton (1974a) used British data for nine groups of consumer goods for the years 1900-1970. He used the values of the likelihood function maximized for the various models. The (symmetric variant of the) Rotterdam system dominates the direct addilog, the L.E.S., and a system with zero substitution matrix, in that order. The additive variant of the Rotterdam model is worse than L.E.S., however, but better than the zero substitution system. 
Theil (1975a) quotes Goldman (1971) who applied the average information inaccuracy measure to predictions of annual British consumer demand for four groups in the period 1950-1955. The three compared models: L.E.S., indirect addilog, and the additive variant of the Rotterdam model were estimated on data for the period 1900-1938. For all groups together, the Rotterdam system is superior to the indirect addilog model, which does better than the L.E.S. The picture is mixed for individual groups, however. For food and beverages and tobacco, the Rotterdam model is better; for durables, the indirect addilog system dominates the Rotterdam system slightly; while the L.E.S. is clearly outstanding for the remainder.

This limited survey suggests that the Rotterdam model dominates its competitors in empirical performance. It remains for the moment an open question to what extent this superiority is significant and to what extent it is due to differences in the number of free parameters. It would be useful to repeat such comparisons for other data and a larger variety of functional forms to find out whether the experience is repeated.

\section{B. Empirical Tests of Theoretical Constraints}

More work has been done to check the empirical validity of the homogeneity, symmetry, and negativity conditions and the assumption of strongly separable preferences. The log-linear model or the Rotterdam system, among others, contain these hypotheses in nested form and are therefore well suited for this purpose.

In Table II an attempt is made to bring together results on more or less formal tests of the various constraints. For several reasons these results have to be interpreted with caution. First of all, the types of tests used are not identical across the different experiments. Secondly, since the testprocedures are usually based on the asymptotic distribution of the test statistic without correction for small sample bias, they are biased towards rejection of the null-hypothesis. Thirdly, there is overlap between the various experiments. Experiments 1 and 6 use almost identical data. The same is true for experiments 3 and 4 . The two countries of experiment 10 are also among those of 7 . Fourthly, the order in which the constraints are introduced can play a role. Usually, symmetry is tested either given homogeneity or together with homogeneity.

With all these caveats in mind one might summarize the findings as follows: Homogeneity passes more easily for small systems than for large ones, where it is usually firmly rejected. Symmetry passes more easily than homogeneity, but it also meets with various rejections. Negativity, given symmetry and homogeneity, does not seem to be very restrictive. Strong separability or additivity appears to be too limiting whenever its empirical validity is checked.

It is not an easy task to explain the rejections. The negative results for homogeneity are most disturbing, since it is in several respects a weak restriction. Absence of dynamic elements in these models could be one reason. However, this 


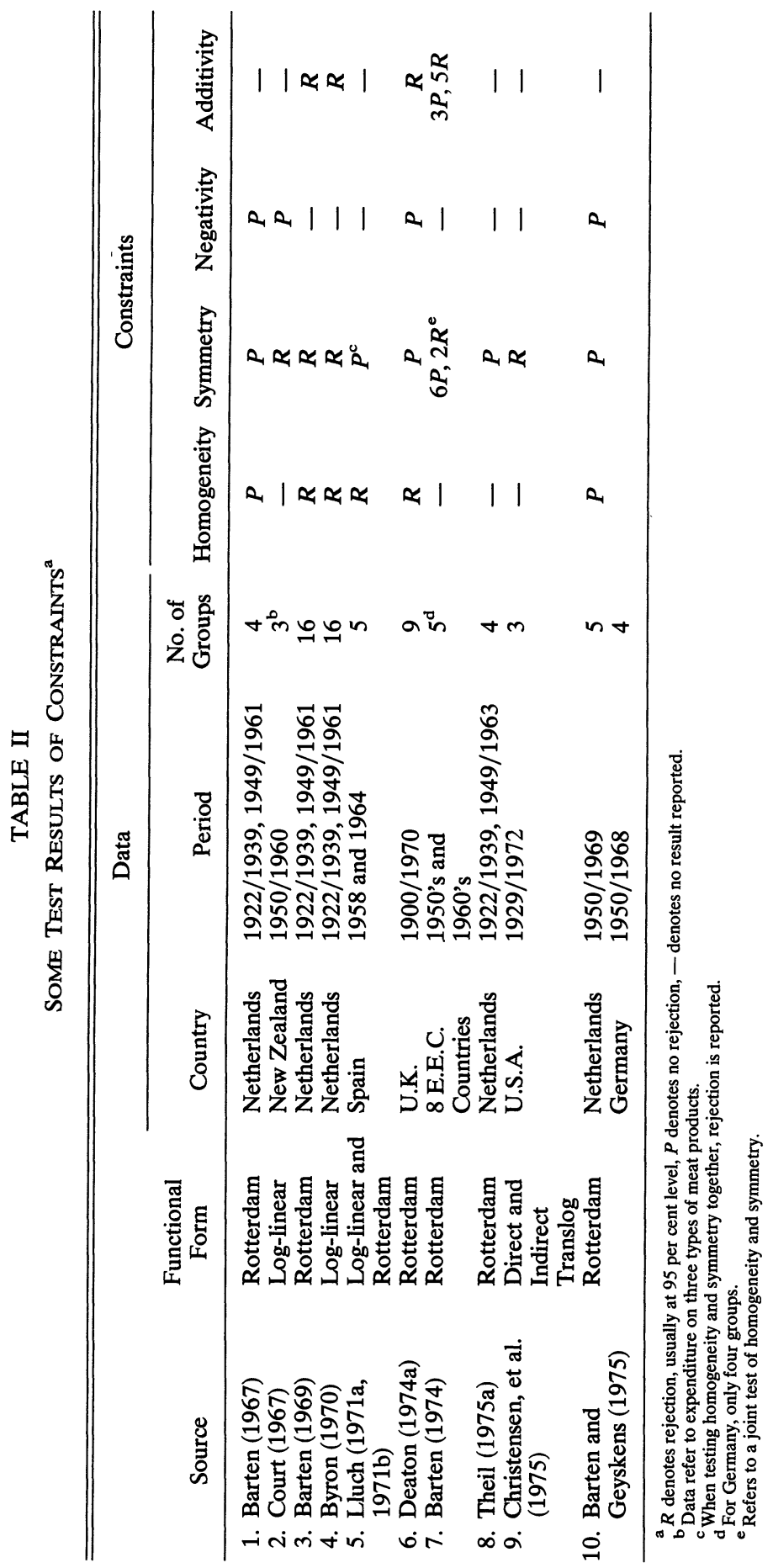


could not explain the rejection in experiment 5. Lluch (1971a, 1971b) used data for 50 urban areas in Spain for two years, namely 1958 and 1964. Adjustment lags should play a minor role when comparing two situations six years apart. There could be a number of other reasons for the rejections. One should avoid concluding that it has been shown once-and for all that individual demand theory is empirically irrelevant when used for the explanation of aggregate demand. With different and richer models the constraints could be useful without being too restrictive on the data. Anyway, the alternative of complete agnosticism is also not attractive.

In conclusion, it may be said that there is a point in not using demand systems where all the restrictions are built in from the start and therefore cannot be tested . on their empirical validity. Frequently, one can then also locate the source of trouble. The test procedures testing a whole set of restrictions at the same time are usually very sensitive to one strong deviation from the null hypothesis. If, for one equation, the null hypothesis of homogeneity has to be rejected firmly, it is rejected for the whole system. The specific nature of the demand for the good in question or the data might be the cause of the negative result. By properly accounting for these the picture could be different.

\section{CONCLUDING REMARKS}

The essence of the consumer demand systems approach consists in providing empirical demand analysis with a conceptual framework to deal with the interdependence of demand for various commodities. In this sense it supplies a bridge between the textbook theory of consumer demand and the empirical work. As this review has indicated, the bridge is there, but it could use some further strengthening. Additional strength might come from considering demand and supply simultaneously. Indeed, one of the justifications of the approach is the need to impose an a priori structure on price effects because the usual price data displays too much collinearity to be able to distinguish between the effects of the individual prices. However, why are prices so collinear? Is it because price setters exploit patterns of complementarity and substitution? It might be that a joint explanation of demand and of prices can supply the answer to these questions. At the same time it would deal with the objection that the consumer demand model concentrates on one side of the market only.

In practice, most of the work on consumer demand systems has been done without explicit reference to its potential use in larger models or for economic policy. However, the potential of such systems, though as yet largely untapped, is clear. In a narrow sense the approach can supply the empirical basis for forecasting and planning of the composition of the demand bundle, for the construction of certain price indexes, for the design of an optimal tax structure, and so on. In a wider sense, the approach can serve as a model to be used in other areas of economic research, like international trade, portfolio composition, producer's 
behavior, and, in general, where allocation aspects are dominating and a relatively well developed theory is available.

\section{Center for Operations Research and Econometrics \\ and \\ Catholic University of Louvain}

Manuscript received September, 1975; revision received April, 1976.

\section{REFERENCES}

Allen, R. G. D. (1934): “A Reconsideration of the Theory of Value, II," Economica, New Series I (1934), 196-219.

Allen, R. G. D., AND A. L. Bowley (1935): Family Expenditure. London: P. S. King and Son, 1935.

BARTen, A. P. (1964): “Consumer Demand Functions under Conditions of Almost Additive Preferences," Econometrica, 32 (1964), 1-38.

(1967): "Evidence on the Slutsky Conditions for Demand Equations," The Review of Economics and Statistics, 49 (1967), 77-84.

(1968): "Estimating Demand Equations," Econometrica, 36 (1968), 213-251.

(1969): "Maximum Likelihood Estimation of a Complete System of Demand Equations," European Economic Review, 1 (1969), 7-73.

(1974): "Complete Systems of Demand Equations: Some Thoughts about Aggregation and Functional Form," Recherches Economiques de Louvain, 40 (1974), 1-18.

BARTEN, A. P., AND E. Geyskens (1975): "The Negativity Condition in Consumer Demand," European Economic Review, 6 (1975), 227-260.

BARTEN, A. P., AND S. J. TuRnOvSKy (1966): "Some Aspects of the Aggregation Problem for Composite Demand Equations," International Economic Review, 7 (1966), 231-259.

BECKER, G. S. (1965): "A Theory of the Allocation of Time," Economic Journal, 75 (1965), 493-517.

BERNDT, E. R., AND N. E. SAVIN (1975): "Estimation and Hypothesis Testing in Singular Equation Systems with Autoregressive Disturbances," Econometrica, 43 (1975), 937-957.

BERNDT, E. R., M. N. DARrough, AND W. E. Diewert (1976): "Flexible Functional Forms and Expenditure Distributions: An Application to Canadian Consumer Demand Functions," Discussion Paper 76-06, Department of Economics, University of British Columbia, 1976.

Blackorby, C., D. Nissen, D. Primont, AND R. R. Russell (1974): "Recursively Decentralized Decision Making," Econometrica, 42 (1974), 487-496.

BRown, A., AND A. DEATON (1972): "Surveys in Applied Economics: Models of Consumer Behaviour," The Economic Journal, 82 (1972), 1145-1236.

BROWN, M., AND D. HEIEN (1972): "The S-Branch Utility Tree: A Generalization of the Linear Expenditure System," Econometrica, 40 (1972), 737-747.

Byron, R. P. (1970): “The Restricted Aitken Estimation of Sets of Demand Relations," Econometrica, 38 (1970), 816-830.

Christensen, L. R., D. W. Jorgenson, AND L. J. LAU (1975): "Transcendental Logarithmic Utility Functions," American Economic Review, 65 (1975), 367-382.

COURT, R. H. (1967): "Utility Maximization and the Demand for New Zealand Meats," Econometrica, 35 (1967), 424-446.

Deaton, A. S. (1974a): "The Analysis of Consumer Demand in the United Kingdom, 1900-1970," Econometrica, 42 (1974), 341-367.

(1974b): "A Reconsideration of the Empirical Implications of Additive Preferences," Economic Journal, 84 (1974), 338-348.

(1974c): "A Simple Non-Additive Model of Demand," mimeographed, Department of Applied Economics, Cambridge University, 1974.

(1975): Models and Projections of Demand in Post-War Britain. London: Chapman and Hall, 1975. 
DIEWERT, W. E. (1974a): “Applications of Duality Theory,” in Frontiers of Quantitative Economics, Vol. II, ed. by M. D. Intriligator and D. Kendrick. Amsterdam: North-Holland, 1974.

(1974b): "Intertemporal Consumer Theory and the Demand for Durables," Econometrica, 42 (1974), 497-516.

Fourgeaud, C., AND A. NATAF (1959): "Consommation en Prix et Revenu Réels et Théorie des Choix," Econometrica, 27 (1959), 329-354.

FRISCH, R. (1959): "A Complete Scheme for Computing All Direct and Cross Demand Elasticities in a Model with Many Sectors," Econometrica, 27 (1959), 177-196.

GoldBerger, A. S. (1969): "Directly Additive Utility and Constant Marginal Budget Shares," Review of Economic Studies, 36 (1969), 251-254.

GoldmaN, S. (1971): "An Empirical Comparison of Alternative Functional Forms of Demand Systems," unpublished doctoral dissertation, The University of Chicago, 1971.

Goldman, S. M., AND H. Uzawa (1964): "A Note on Separability in Demand Analysis," Econometrica, 32 (1964), 387-398.

GORMAN, W. M. (1959a): "Separable Utility and Aggregation," Econometrica, 27 (1959), 469-481. (1959b): "The Demand for Fish, An Application of Factor Analysis," Research Paper 6, Series A, Faculty of Commerce and Social Science, University of Birmingham, 1959.

(1973): "The Demand for Related Goods," paper read at the Conference on Consumer Behavior organized by the Economics Committee of the Social Sciences Research Council, October, 1973.

HANOCH, G. (1975): "Production and Demand Models with Direct or Indirect Implicit Additivity," Econometrica, 43 (1975), 395-420.

Hicks, J. R. (1934): "A Reconsideration of the Theory of Value I," Economica, New Series 1 (1934), 52-75.

HOUTHAKKeR, H. S. (1960): “Additive Preferences," Econometrica, 28 (1960), 244-257.

(1965): “A Note on Self-Dual Preferences," Econometrica, 33 (1965), 797-801.

Houthakker, H. S., AND L. D. TAYlor (1965): Consumer Demand in the United States 1929-1970. Cambridge, Mass.: Harvard University Press, 1965.

JoHANSEN, L. (1969): "On the Relationships between Some Systems of Demand Functions," Liiketaloudellinen Aikakauskirga, 1 (1969), 30-41.

KATZNER, D. W. (1968): "A Note on the Differentiability of Consumer Demand Functions," Econometrica, 36 (1968), 415-418. (1970): Static Demand Theory. London: Macmillan, 1970.

KLEIN, L. R., AND H. RuBIN (1949): “A Constant-Utility Index of the Cost of Living,” The Review of Economic Studies, 15 (1949), 84-87.

LANCASTER, J. (1966): “A New Approach to Consumer Theory,” Journal of Political Economy, 74 (1966), 132-157.

LAU L. J. (1974): "Applications of Duality Theory: Comments," in Frontiers of Quantitative Economics, Vol. II, ed. by M. D. Intriligator and D. A. Kendrick. Amsterdam: North-Holland, 1974.

(1976): "Empirical Approaches to Systems of Consumer Demand Functions through Duality," in Frontiers of Quantitative Economics, Vol. III, ed. by M. D. Intriligator. Amsterdam: North-Holland, 1976.

LEE, F. Y. (1970): "Estimation of Dynamic Demand Relations from Time Series of Family Budget Data," Journal of the American Statistical Association, 65 (1970), 586-597.

LEONTIEF, W. (1947a): "A Note on the Interrelation of Subsets of Independent Variables of a Continuous Function with Continuous First Derivatives," Bulletin of the American Mathemati cal Society, 53 (1947), 343-350.

(1947b): "Introduction to a Theory of the Internal Structure of Functional Relationships," Econometrica, 15 (1947), 361-373.

LESER, C. E. V. (1941): "Family Budget Data and Price Elasticities of Demand," Review of Economic Studies, 9 (1941), 40-57.

(1958): "The Pattern of Australian Demand," The Economic Record, 34 (1958), 212-222.

(1960): "Demand Functions for Nine Commodity Groups in Australia," The Australian Journal of Statistics, 2 (1960), 102-113.

(1961): "Commodity Group Expenditure Functions for the United Kingdom, 1948-57," Econometrica, 29 (1961), 24-32.

Lluch, C. (1971a): La Demanda de Bienes de Consumo, Teoria y Aplicacion a España. Madrid: Confederacion Española de Cajas de Ahorros, 1971. 
(1971b): “Consumer Demand Functions, Spain, 1956-1964,” European Economic Review, 2 (1971), 277-302.

(1973): "The Extended Linear Expenditure System," European Economic Review, 4 (1973), 21-32.

(1974): "Expenditure, Savings and Habit Formation," International Economic Review, 15 (1974), 786-797.

MCFADDEN, D. (1964): “Existence Conditions for Theil-type Preferences," mimeographed, Department of Economics, University of California, Berkeley, 1964.

Muellbauer, J. (1975): "Aggregation, Income Distribution and Consumer Demand," The Review of Economic Studies, 42 (1975), 525-543.

NASSE. PH. (1973): "Un Système Complet de Fonctions de Demande: les Équations de Fourgeaud et Nataf," Econometrica, 41 (1973), 1137-1158.

PARKs, R. W. (1969): "Systems of Demand Equations: An Empirical Comparison of Alternative Functional Forms," Econometrica, 37 (1969), 629-650.

PEARCE, I. F. (1961): “An Exact Method of Consumer Demand Analysis,” Econometrica, 29 (1961) 499-516.

(1964): A Contribution to Demand Analysis. Oxford: Clarendon Press, 1964.

PhLIPS, L. (1971): "Substitution, Complementarity, and the Residual Variation Around Dynamic Demand Equations," American Economic Review, 61 (1971), 586-597.

(1972): "A Dynamic Version of the Linear Expenditure Model," Review of Economics and Statistics, 54 (1972), 450-458.

(1974): Applied Consumption Analysis. Amsterdam: North-Holland, 1974.

Phlips, L., AND PH. Rouzier (1972): "Substitution, Complementarity, and the Residual Variation: Some Further Results," American Economic Review, 62 (1972), 747-751.

Pigou, A. C. (1910): "A Method of Determining the Numerical Value of Elasticities of Demand," Economic Journal, 20 (1910), 636-640.

PollAK, R. A. (1972): “Generalized Separability,” Econometrica, 40 (1972), 431-453.

Pollak, R. A., AND T. J. WAlEs (1969): "Estimation of the Linear Expenditure System," Econometrica, 37 (1969), 611-628.

Powell, A. (1966): "A Complete System of Consumer Demand Equations for the Australian Economy Fitted by a Model of Additive Preferences," Econometrica, 34 (1966), 661-675. (1974): Empirical Analytics of Demand Systems. Lexington: Heath, 1974.

Rossier, E. (1974): Contribution aux Explications Dynamiques de la Consommation Semi-Agrégée. Berne: Lang, 1974.

Roy, R. (1942): De l'Utilité. Contribution à la Théorie des Choix. Paris: Hermann, 1942.

SALVAS-BRONSARD, L., D. LEBLANC, Y. ZARRA, AND C. BRONSARD (1973): "The Rotterdam Model and the Negativity of the Slutsky Matrix." Cahier ${ }^{\circ} 7312$, Département de Sciences Economiques, Université de Montréal, 1973.

SAmuelson, P. A. (1947): Foundations of Economic Analysis. Cambridge, Mass.: Harvard University Press, 1947.

SATO, K. (1972): "Additive Utility Functions with Double-Log Consumer Demand Functions," Journal of Political Economy, 80 (1972), 102-124.

SolARI, L. (1971): Théorie des Choix et Fonctions de Consommation Semi-Agrégées. Genève: Droz, 1971.

SOMERMEYER, W. H., AND R. BANNInK (1973): A Consumption-Savings Model and Its Applications. Amsterdam: North-Holland, 1973.

SOMERMEYER, W. H., G. M. HilHORST, AND J. W. W. A. Wit (1962): “A Method of Estimating Price and Income Elasticities from Time Series and Its Application to Consumers' Expenditures in the Netherlands, 1949-1959," Statistical Studies n ${ }^{\circ} 13$, Central Bureau of Statistics, The Hague, 1962.

SOMERMEYER, W. H., AND A. LANGHOUT (1972): "Shapes of Engel Curves and Demand Curves; Implications of the Expenditure Allocation Model Applied to Dutch Data," European Economic Review, 3 (1972), 351-386.

SOMERMEYER, W. H., AND J. W. W. A. Wit (1956): "Een 'Verdeel'-Model," Rapport M 14, Centraal Bureau voor de Statistiek, 's-Gravenhage, June 22, 1956, unpublished.

Sono, M. (1945): "The Effect of Price Changes on the Demand and Supply of Separable Goods," International Economic Review, 2 (1960), 239-271; translation of the Japanese version published in Kokumni Keizai Zasski, 74 (1945), 1-51. 
Stone, R. (1954): "Linear Expenditure Systems and Demand Analysis: An Application to the Pattern of British Demand," The Economic Journal, 64 (1954), 511-527.

STRotz, R. H. (1957): “The Empirical Implications of a Utility Tree," Econometrica, 25 (1957), 269-280.

- (1959): "The Utility Tree-A Correction and Further Appraisal," Econometrica, 27 (1959), 482-488.

TAYloR, L. D., AND D. Weiserbs (1972): “On the Estimation of Dynamic Demand Functions," Review of Economics and Statistics, 54 (1972), 459-465.

TheIL, H. (1965): "The Information Approach to Demand Analysis," Econometrica, 33 (1965), 67-87.

(1967): Economics and Information Theory. Amsterdam: North-Holland, 1967.

(1971a): "An Economic Theory of the Second Moments of Disturbances of Behavioral Equations," The American Economic Review, 61 (1971), 190-194. (1971b): Principles of Econometrics. Amsterdam: North-Holland, 1971.

(1975a): Theory and Measurement of Consumer Demand, Vol. I. Amsterdam: North-Holland, 1975.

(1975b): "The Theory of Rational Random Behavior and Its Application to Demand Analysis," European Economic Review, 6 (1975), 217-226.

(1976): Theory and Measurement of Consumer Demand, Vol. II. Amsterdam: North-Holland, 1976.

TheIl, H., AND H. NEUdeCKer (1957): "Substitution, Complementarity and the Residual Variation around Engel Curves," The Review of Economic Studies, 25 (1957), 114-123.

VINCI, S. (1967): "La Domar.da dei Beni di Consumo in Italia dal 1953 al 1964-Analisi Econometrica," Giornale degli Economisti e Annali di Economia, 26 (1967), 361-400.

ZELLNER, A. (1962): "An Efficient Method of Estimating Seemingly Unrelated Regressions and Tests for Aggregation Bias," Journal of the American Statistical Association, 57 (1962), 348-368. 
http://www.jstor.org

\title{
LINKED CITATIONS
}

\author{
- Page 1 of 13 -
}

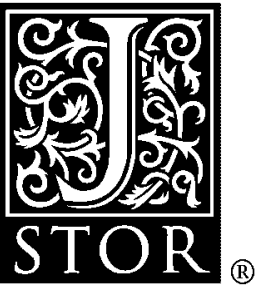

You have printed the following article:

The Systems of Consumer Demand Functions Approach: A Review

Anton P. Barten

Econometrica, Vol. 45, No. 1. (Jan., 1977), pp. 23-50.

Stable URL:

http://links.jstor.org/sici?sici=0012-9682\%28197701\%2945\%3A1\%3C23\%3ATSOCDF\%3E2.0.CO\%3B2-B

This article references the following linked citations. If you are trying to access articles from an off-campus location, you may be required to first logon via your library web site to access JSTOR. Please visit your library's website or contact a librarian to learn about options for remote access to JSTOR.

\section{[Footnotes]}

\author{
${ }^{2}$ Surveys in Applied Economics: Models of Consumer Behaviour \\ Alan Brown; Angus Deaton \\ The Economic Journal, Vol. 82, No. 328. (Dec., 1972), pp. 1145-1236. \\ Stable URL: \\ http://links.jstor.org/sici?sici=0013-0133\%28197212\%2982\%3A328\%3C1145\%3ASIAEMO\%3E2.0.CO\%3B2-1 \\ ${ }^{9}$ Production and Demand Models with Direct or Indirect Implicit Additivity \\ Giora Hanoch \\ Econometrica, Vol. 43, No. 3. (May, 1975), pp. 395-419. \\ Stable URL: \\ http://links.jstor.org/sici?sici=0012-9682\%28197505\%2943\%3A3\%3C395\%3APADMWD\%3E2.0.CO\%3B2-A

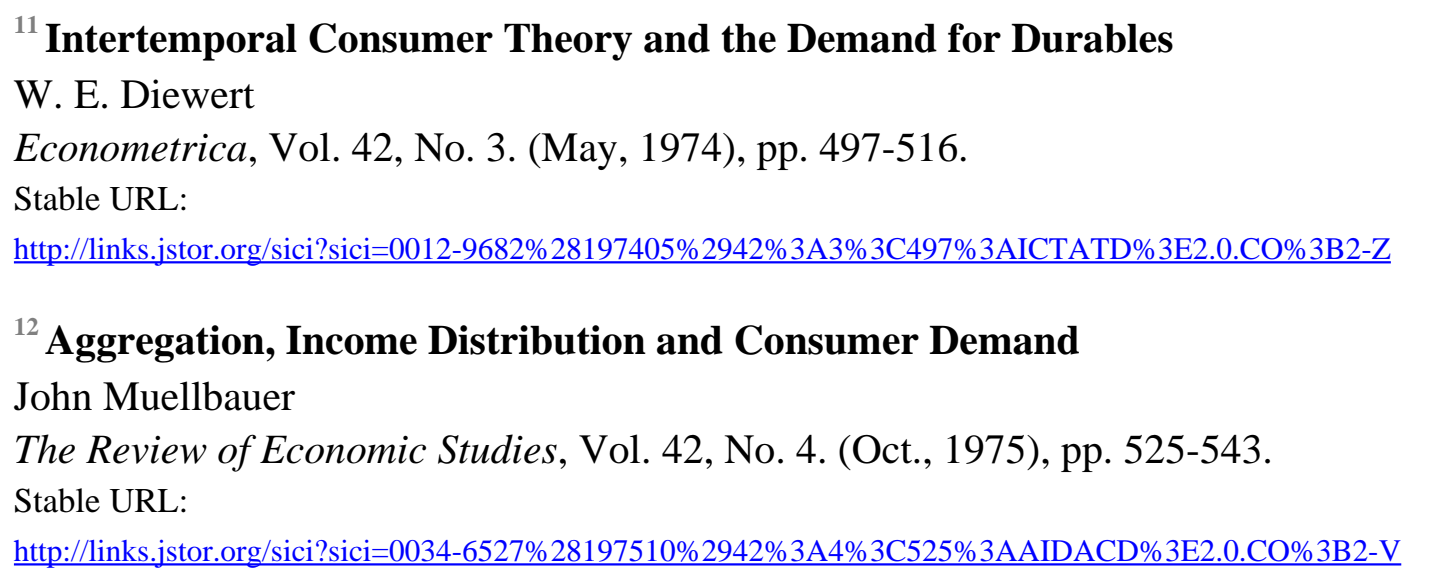

NOTE: The reference numbering from the original has been maintained in this citation list. 
http://www.jstor.org

\title{
LINKED CITATIONS
}

\author{
- Page 2 of 13 -
}

\footnotetext{
${ }^{13}$ Estimation of Dynamic Demand Relations from a Time Series of Family Budget Data Feng-Yao Lee

Journal of the American Statistical Association, Vol. 65, No. 330. (Jun., 1970), pp. 586-597.

Stable URL:

http://links.jstor.org/sici?sici=0162-1459\%28197006\%2965\%3A330\%3C586\%3AEODDRF\%3E2.0.CO\%3B2-K
}

\author{
${ }^{13}$ A Dynamic Version of The Linear Expenditure Model \\ Louis Phlips \\ The Review of Economics and Statistics, Vol. 54, No. 4. (Nov., 1972), pp. 450-458. \\ Stable URL: \\ http://links.jstor.org/sici?sici=0034-6535\%28197211\%2954\%3A4\%3C450\%3AADVOTL\%3E2.0.CO\%3B2-G
}

\author{
${ }^{13}$ On the Estimation of Dynamic Demand Functions \\ Lester D. Taylor; Daniel Weiserbs \\ The Review of Economics and Statistics, Vol. 54, No. 4. (Nov., 1972), pp. 459-465. \\ Stable URL: \\ http://links.jstor.org/sici?sici=0034-6535\%28197211\%2954\%3A4\%3C459\%3AOTEODD\%3E2.0.CO\%3B2-2
}

\section{${ }^{14}$ Expenditure, Savings and Habit Formation}

Constantino Lluch

International Economic Review, Vol. 15, No. 3. (Oct., 1974), pp. 786-797.

Stable URL:

http://links.jstor.org/sici?sici=0020-6598\%28197410\%2915\%3A3\%3C786\%3AESAHF\%3E2.0.CO\%3B2-O

\section{${ }^{15}$ Intertemporal Consumer Theory and the Demand for Durables}

W. E. Diewert

Econometrica, Vol. 42, No. 3. (May, 1974), pp. 497-516.

Stable URL:

http://links.jstor.org/sici?sici=0012-9682\%28197405\%2942\%3A3\%3C497\%3AICTATD\%3E2.0.CO\%3B2-Z

\author{
${ }^{15}$ Aggregation, Income Distribution and Consumer Demand \\ John Muellbauer \\ The Review of Economic Studies, Vol. 42, No. 4. (Oct., 1975), pp. 525-543. \\ Stable URL: \\ http://links.jstor.org/sici?sici=0034-6527\%28197510\%2942\%3A4\%3C525\%3AAIDACD\%3E2.0.CO\%3B2-V
}

NOTE: The reference numbering from the original has been maintained in this citation list. 
http://www.jstor.org

\title{
LINKED CITATIONS
}

\author{
- Page 3 of 13 -
}

\section{${ }^{16}$ Transcendental Logarithmic Utility Functions}

Laurits R. Christensen; Dale W. Jorgenson; Lawrence J. Lau

The American Economic Review, Vol. 65, No. 3. (Jun., 1975), pp. 367-383.

Stable URL:

http://links.jstor.org/sici?sici=0002-8282\%28197506\%2965\%3A3\%3C367\%3ATLUF\%3E2.0.CO\%3B2-F

${ }^{18}$ Production and Demand Models with Direct or Indirect Implicit Additivity

Giora Hanoch

Econometrica, Vol. 43, No. 3. (May, 1975), pp. 395-419.

Stable URL:

http://links.jstor.org/sici?sici=0012-9682\%28197505\%2943\%3A3\%3C395\%3APADMWD\%3E2.0.CO\%3B2-A

\section{${ }^{19}$ Transcendental Logarithmic Utility Functions}

Laurits R. Christensen; Dale W. Jorgenson; Lawrence J. Lau

The American Economic Review, Vol. 65, No. 3. (Jun., 1975), pp. 367-383.

Stable URL:

http://links.jstor.org/sici?sici=0002-8282\%28197506\%2965\%3A3\%3C367\%3ATLUF\%3E2.0.CO\%3B2-F

${ }^{19}$ Intertemporal Consumer Theory and the Demand for Durables

W. E. Diewert

Econometrica, Vol. 42, No. 3. (May, 1974), pp. 497-516.

Stable URL:

http://links.jstor.org/sici?sici=0012-9682\%28197405\%2942\%3A3\%3C497\%3AICTATD\%3E2.0.CO\%3B2-Z

\section{${ }^{20}$ Evidence on the Slutsky Conditions for Demand Equations}

A. P. Barten

The Review of Economics and Statistics, Vol. 49, No. 1. (Feb., 1967), pp. 77-84.

Stable URL:

http://links.jstor.org/sici?sici=0034-6535\%28196702\%2949\%3A1\%3C77\%3AEOTSCF\%3E2.0.CO\%3B2-P

\section{${ }^{20}$ Estimating Demand Equations}

A. P. Barten

Econometrica, Vol. 36, No. 2. (Apr., 1968), pp. 213-251.

Stable URL:

http://links.jstor.org/sici?sici=0012-9682\%28196804\%2936\%3A2\%3C213\%3AEDE\%3E2.0.CO\%3B2-J

NOTE: The reference numbering from the original has been maintained in this citation list. 
http://www.jstor.org

\title{
LINKED CITATIONS
}

\author{
- Page 4 of 13 -
}

\section{${ }^{20}$ Some Aspects of the Aggregation Problem for Composite Demand Equations}

A. P. Barten; S. J. Turnovsky

International Economic Review, Vol. 7, No. 3. (Sep., 1966), pp. 231-259.

Stable URL:

http://links.jstor.org/sici?sici=0020-6598\%28196609\%297\%3A3\%3C231\%3ASAOTAP\%3E2.0.CO\%3B2-K

\section{References}

\section{Review: [Untitled]}

Reviewed Work(s):

Pitfalls in the Statistical Construction of Demand and Supply Curves by Ragnar Frisch R. G. D. Allen

Economica, New Series, Vol. 1, No. 3. (Aug., 1934), pp. 342-344.

Stable URL:

http://links.jstor.org/sici?sici=0013-0427\%28193408\%292\%3A1\%3A3\%3C342\%3APITSCO\%3E2.0.CO\%3B2-V

Consumer Demand Functions under Conditions of Almost Additive Preferences

A. P. Barten

Econometrica, Vol. 32, No. 1/2. (Jan. - Apr., 1964), pp. 1-38.

Stable URL:

http://links.jstor.org/sici?sici=0012-9682\%28196401\%2F04\%2932\%3A1\%2F2\%3C1\%3ACDFUCO\%3E2.0.CO\%3B2-K

\section{Evidence on the Slutsky Conditions for Demand Equations}

\section{A. P. Barten}

The Review of Economics and Statistics, Vol. 49, No. 1. (Feb., 1967), pp. 77-84.

Stable URL:

http://links.jstor.org/sici?sici=0034-6535\%28196702\%2949\%3A1\%3C77\%3AEOTSCF\%3E2.0.CO\%3B2-P

\section{Estimating Demand Equations}

A. P. Barten

Econometrica, Vol. 36, No. 2. (Apr., 1968), pp. 213-251.

Stable URL:

http://links.jstor.org/sici?sici=0012-9682\%28196804\%2936\%3A2\%3C213\%3AEDE\%3E2.0.CO\%3B2-J

NOTE: The reference numbering from the original has been maintained in this citation list. 
http://www.jstor.org

\title{
LINKED CITATIONS
}

\author{
- Page 5 of 13 -
}

Some Aspects of the Aggregation Problem for Composite Demand Equations

A. P. Barten; S. J. Turnovsky

International Economic Review, Vol. 7, No. 3. (Sep., 1966), pp. 231-259.

Stable URL:

http://links.jstor.org/sici?sici=0020-6598\%28196609\%297\%3A3\%3C231\%3ASAOTAP\%3E2.0.CO\%3B2-K

\section{A Theory of the Allocation of Time}

Gary S. Becker

The Economic Journal, Vol. 75, No. 299. (Sep., 1965), pp. 493-517.

Stable URL:

http://links.jstor.org/sici?sici=0013-0133\%28196509\%2975\%3A299\%3C493\%3AATOTAO\%3E2.0.CO\%3B2-N

Estimation and Hypothesis Testing in Singular Equation Systems with Autoregressive Disturbances

Ernst R. Berndt; N. Eugene Savin

Econometrica, Vol. 43, No. 5/6. (Sep. - Nov., 1975), pp. 937-958.

Stable URL:

http://links.jstor.org/sici?sici=0012-9682\%28197509\%2F11\%2943\%3A5\%2F6\%3C937\%3AEAHTIS\%3E2.0.CO\%3B2-7

\section{Recursively Decentralized Decision Making}

Charles Blackorby; David Nissen; Daniel Primont; R. Robert Russell

Econometrica, Vol. 42, No. 3. (May, 1974), pp. 487-496.

Stable URL:

http://links.jstor.org/sici?sici=0012-9682\%28197405\%2942\%3A3\%3C487\%3ARDDM\%3E2.0.CO\%3B2-0

\section{Surveys in Applied Economics: Models of Consumer Behaviour}

Alan Brown; Angus Deaton

The Economic Journal, Vol. 82, No. 328. (Dec., 1972), pp. 1145-1236.

Stable URL:

http://links.jstor.org/sici?sici=0013-0133\%28197212\%2982\%3A328\%3C1145\%3ASIAEMO\%3E2.0.CO\%3B2-1

The S-Branch Utility Tree: A Generalization of the Linear Expenditure System

Murray Brown; Dale Heien

Econometrica, Vol. 40, No. 4. (Jul., 1972), pp. 737-747.

Stable URL:

http://links.jstor.org/sici?sici=0012-9682\%28197207\%2940\%3A4\%3C737\%3ATSUTAG\%3E2.0.CO\%3B2-I

NOTE: The reference numbering from the original has been maintained in this citation list. 
http://www.jstor.org

\title{
LINKED CITATIONS
}

\author{
- Page 6 of 13 -
}

The Restricted Aitken Estimation of Sets of Demand Relations

R. P. Byron

Econometrica, Vol. 38, No. 6. (Nov., 1970), pp. 816-830.

Stable URL:

http://links.jstor.org/sici?sici=0012-9682\%28197011\%2938\%3A6\%3C816\%3ATRAEOS\%3E2.0.CO\%3B2-L

\section{Transcendental Logarithmic Utility Functions}

Laurits R. Christensen; Dale W. Jorgenson; Lawrence J. Lau

The American Economic Review, Vol. 65, No. 3. (Jun., 1975), pp. 367-383.

Stable URL:

http://links.jstor.org/sici?sici=0002-8282\%28197506\%2965\%3A3\%3C367\%3ATLUF\%3E2.0.CO\%3B2-F

\section{Utility Maximization and the Demand for New Zealand Meats}

Robin H. Court

Econometrica, Vol. 35, No. 3/4. (Jul. - Oct., 1967), pp. 424-446.

Stable URL:

http://links.jstor.org/sici?sici=0012-9682\%28196707\%2F10\%2935\%3A3\%2F4\%3C424\%3AUMATDF\%3E2.0.CO\%3B2-S

The Analysis of Consumer Demand in the United Kingdom, 1900-1970

Angus S. Deaton

Econometrica, Vol. 42, No. 2. (Mar., 1974), pp. 341-367.

Stable URL:

http://links.jstor.org/sici?sici=0012-9682\%28197403\%2942\%3A2\%3C341\%3ATAOCDI\%3E2.0.CO\%3B2-M

\section{Review: [Untitled]}

Reviewed Work(s):

Permanent Income, Wealth, and Consumption. by Thomas Mayer

Angus Deaton

The Economic Journal, Vol. 84, No. 333. (Mar., 1974), pp. 200-202.

Stable URL:

http://links.jstor.org/sici?sici=0013-0133\%28197403\%2984\%3A333\%3C200\%3APIWAC\%3E2.0.CO\%3B2-F

\section{Intertemporal Consumer Theory and the Demand for Durables}

W. E. Diewert

Econometrica, Vol. 42, No. 3. (May, 1974), pp. 497-516.

Stable URL:

http://links.jstor.org/sici?sici=0012-9682\%28197405\%2942\%3A3\%3C497\%3AICTATD\%3E2.0.CO\%3B2-Z

NOTE: The reference numbering from the original has been maintained in this citation list. 
http://www.jstor.org

\title{
LINKED CITATIONS
}

\author{
- Page 7 of 13 -
}

Consommation en Prix et Revenu Reels et Theorie des Choix

C. Fourgeaud; A. Nataf

Econometrica, Vol. 27, No. 3. (Jul., 1959), pp. 329-354.

Stable URL:

http://links.jstor.org/sici?sici=0012-9682\%28195907\%2927\%3A3\%3C329\%3ACEPERR\%3E2.0.CO\%3B2-Q

A Complete Scheme for Computing All Direct and Cross Demand Elasticities in a Model with Many Sectors

Ragnar Frisch

Econometrica, Vol. 27, No. 2. (Apr., 1959), pp. 177-196.

Stable URL:

http://links.jstor.org/sici?sici=0012-9682\%28195904\%2927\%3A2\%3C177\%3AACSFCA\%3E2.0.CO\%3B2-J

\section{Directly Additive Utility and Constant Marginal Budget Shares}

A. S. Goldberger

The Review of Economic Studies, Vol. 36, No. 2. (Apr., 1969), pp. 251-254.

Stable URL:

http://links.jstor.org/sici?sici=0034-6527\%28196904\%2936\%3A2\%3C251\%3ADAUACM\%3E2.0.CO\%3B2-M

\author{
A Note on Separability in Demand Analysis \\ S. M. Goldman; H. Uzawa \\ Econometrica, Vol. 32, No. 3. (Jul., 1964), pp. 387-398. \\ Stable URL: \\ http://links.jstor.org/sici?sici=0012-9682\%28196407\%2932\%3A3\%3C387\%3AANOSID\%3E2.0.CO\%3B2-B
}

\section{Separable Utility and Aggregation}

W. M. Gorman

Econometrica, Vol. 27, No. 3. (Jul., 1959), pp. 469-481.

Stable URL:

http://links.jstor.org/sici?sici=0012-9682\%28195907\%2927\%3A3\%3C469\%3ASUAA\%3E2.0.CO\%3B2-A

\section{Production and Demand Models with Direct or Indirect Implicit Additivity}

Giora Hanoch

Econometrica, Vol. 43, No. 3. (May, 1975), pp. 395-419.

Stable URL:

http://links.jstor.org/sici?sici=0012-9682\%28197505\%2943\%3A3\%3C395\%3APADMWD\%3E2.0.CO\%3B2-A

NOTE: The reference numbering from the original has been maintained in this citation list. 
http://www.jstor.org

\title{
LINKED CITATIONS
}

\author{
- Page 8 of 13 -
}

\section{A Reconsideration of the Theory of Value. Part I}

J. R. Hicks; R. G. D. Allen

Economica, New Series, Vol. 1, No. 1. (Feb., 1934), pp. 52-76.

Stable URL:

http://links.jstor.org/sici?sici=0013-0427\%28193402\%292\%3A1\%3A1\%3C52\%3AAROTTO\%3E2.0.CO\%3B2-P

\section{Additive Preferences}

H. S. Houthakker

Econometrica, Vol. 28, No. 2. (Apr., 1960), pp. 244-257.

Stable URL:

http://links.jstor.org/sici?sici=0012-9682\%28196004\%2928\%3A2\%3C244\%3AAP\%3E2.0.CO\%3B2-K

\section{A Note on Self-Dual Preferences}

H. S. Houthakker

Econometrica, Vol. 33, No. 4. (Oct., 1965), pp. 797-801.

Stable URL:

http://links.jstor.org/sici?sici=0012-9682\%28196510\%2933\%3A4\%3C797\%3AANOSP\%3E2.0.CO\%3B2-8

\section{A Note on the Differentiability of Consumer Demand Functions}

Donald W. Katzner

Econometrica, Vol. 36, No. 2. (Apr., 1968), pp. 415-418.

Stable URL:

http://links.jstor.org/sici?sici=0012-9682\%28196804\%2936\%3A2\%3C415\%3AANOTDO\%3E2.0.CO\%3B2-X

\section{A Constant-Utility Index of the Cost of Living}

L. R. Klein; H. Rubin

The Review of Economic Studies, Vol. 15, No. 2. (1947 - 1948), pp. 84-87.

Stable URL:

http://links.jstor.org/sici?sici=0034-6527\%281947\%2F1948\%2915\%3A2\%3C84\%3AACIOTC\%3E2.0.CO\%3B2-B

\section{A New Approach to Consumer Theory}

Kelvin J. Lancaster

The Journal of Political Economy, Vol. 74, No. 2. (Apr., 1966), pp. 132-157.

Stable URL:

http://links.jstor.org/sici?sici=0022-3808\%28196604\%2974\%3A2\%3C132\%3AANATCT\%3E2.0.CO\%3B2-P

NOTE: The reference numbering from the original has been maintained in this citation list. 
http://www.jstor.org

\title{
LINKED CITATIONS
}

\author{
- Page 9 of 13 -
}

Estimation of Dynamic Demand Relations from a Time Series of Family Budget Data

Feng-Yao Lee

Journal of the American Statistical Association, Vol. 65, No. 330. (Jun., 1970), pp. 586-597.

Stable URL:

http://links.jstor.org/sici?sici=0162-1459\%28197006\%2965\%3A330\%3C586\%3AEODDRF\%3E2.0.CO\%3B2-K

Introduction to a Theory of the Internal Structure of Functional Relationships

Wassily Leontief

Econometrica, Vol. 15, No. 4. (Oct., 1947), pp. 361-373.

Stable URL:

http://links.jstor.org/sici?sici=0012-9682\%28194710\%2915\%3A4\%3C361\%3AITATOT\%3E2.0.CO\%3B2-6

Family Budget Data and Price-Elasticities of Demand

C. E. V. Leser

The Review of Economic Studies, Vol. 9, No. 1. (Nov., 1941), pp. 40-57.

Stable URL:

http://links.jstor.org/sici?sici=0034-6527\%28194111\%299\%3A1\%3C40\%3AFBDAPO\%3E2.0.CO\%3B2-1

Commodity Group Expenditure Functions for the United Kingdom, 1948-1957

C. E. V. Leser

Econometrica, Vol. 29, No. 1. (Jan., 1961), pp. 24-32.

Stable URL:

http://links.jstor.org/sici?sici=0012-9682\%28196101\%2929\%3A1\%3C24\%3ACGEFFT\%3E2.0.CO\%3B2-J

\section{Expenditure, Savings and Habit Formation}

Constantino Lluch

International Economic Review, Vol. 15, No. 3. (Oct., 1974), pp. 786-797.

Stable URL:

http://links.jstor.org/sici?sici=0020-6598\%28197410\%2915\%3A3\%3C786\%3AESAHF\%3E2.0.CO\%3B2-O

\section{Aggregation, Income Distribution and Consumer Demand}

John Muellbauer

The Review of Economic Studies, Vol. 42, No. 4. (Oct., 1975), pp. 525-543.

Stable URL:

http://links.jstor.org/sici?sici=0034-6527\%28197510\%2942\%3A4\%3C525\%3AAIDACD\%3E2.0.CO\%3B2-V

NOTE: The reference numbering from the original has been maintained in this citation list. 
http://www.jstor.org

\section{LINKED CITATIONS}

- Page 10 of 13 -

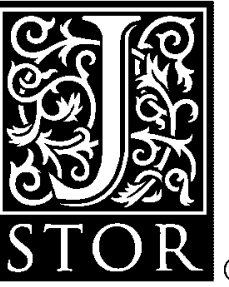

Un Systeme Complet de Fonctions de Demande: Les Equations de Fourgeaud et Nataf $\mathrm{Ph}$. Nasse

Econometrica, Vol. 41, No. 6. (Nov., 1973), pp. 1137-1158.

Stable URL:

http://links.jstor.org/sici?sici=0012-9682\%28197311\%2941\%3A6\%3C1137\%3AUSCDFD\%3E2.0.CO\%3B2-A

Systems of Demand Equations: An Empirical Comparison of Alternative Functional Forms Richard W. Parks

Econometrica, Vol. 37, No. 4. (Oct., 1969), pp. 629-650.

Stable URL:

http://links.jstor.org/sici?sici=0012-9682\%28196910\%2937\%3A4\%3C629\%3ASODEAE\%3E2.0.CO\%3B2-N

\section{An Exact Method of Consumer Demand Analysis}

I. F. Pearce

Econometrica, Vol. 29, No. 4. (Oct., 1961), pp. 499-516.

Stable URL:

http://links.jstor.org/sici?sici=0012-9682\%28196110\%2929\%3A4\%3C499\%3AAEMOCD\%3E2.0.CO\%3B2-2

Substitution, Complementarity, and the Residual Variation Around Dynamic Demand Equations

Louis Phlips

The American Economic Review, Vol. 61, No. 4. (Sep., 1971), pp. 586-597.

Stable URL:

http://links.jstor.org/sici?sici=0002-8282\%28197109\%2961\%3A4\%3C586\%3ASCATRV\%3E2.0.CO\%3B2-B

\section{A Dynamic Version of The Linear Expenditure Model}

Louis Phlips

The Review of Economics and Statistics, Vol. 54, No. 4. (Nov., 1972), pp. 450-458.

Stable URL:

http://links.jstor.org/sici?sici=0034-6535\%28197211\%2954\%3A4\%3C450\%3AADVOTL\%3E2.0.CO\%3B2-G

Substitution, Complementarity, and the Residual Variation: Some Further Results

Louis Phlips; Philippe Rouzier

The American Economic Review, Vol. 62, No. 4. (Sep., 1972), pp. 747-751.

Stable URL:

http://links.jstor.org/sici?sici=0002-8282\%28197209\%2962\%3A4\%3C747\%3ASCATRV\%3E2.0.CO\%3B2-G

NOTE: The reference numbering from the original has been maintained in this citation list. 
http://www.jstor.org

\section{LINKED CITATIONS}

- Page 11 of 13 -

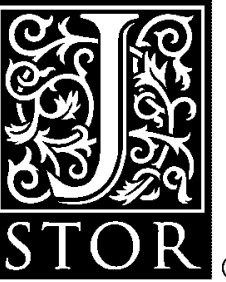

\section{A Method of Determining the Numerical Value of Elasticities of Demand}

A. C. Pigou

The Economic Journal, Vol. 20, No. 80. (Dec., 1910), pp. 636-640.

Stable URL:

http://links.jstor.org/sici?sici=0013-0133\%28191012\%2920\%3A80\%3C636\%3AAMODTN\%3E2.0.CO\%3B2-0

\section{Generalized Separability}

Robert A. Pollak

Econometrica, Vol. 40, No. 3. (May, 1972), pp. 431-453.

Stable URL:

http://links.jstor.org/sici?sici=0012-9682\%28197205\%2940\%3A3\%3C431\%3AGS\%3E2.0.CO\%3B2-0

\section{Estimation of the Linear Expenditure System}

Robert A. Pollak; Terence J. Wales

Econometrica, Vol. 37, No. 4. (Oct., 1969), pp. 611-628.

Stable URL:

http://links.jstor.org/sici?sici=0012-9682\%28196910\%2937\%3A4\%3C611\%3AEOTLES\%3E2.0.CO\%3B2-2

A Complete System of Consumer Demand Equations for the Australian Economy Fitted by a Model of Additive Preferences

Alan Powell

Econometrica, Vol. 34, No. 3. (Jul., 1966), pp. 661-675.

Stable URL:

http://links.jstor.org/sici?sici=0012-9682\%28196607\%2934\%3A3\%3C661\%3AACSOCD\%3E2.0.CO\%3B2-M

\section{Additive Utility Functions with Double-Log Consumer Demand Functions}

Kazuo Sato

The Journal of Political Economy, Vol. 80, No. 1. (Jan. - Feb., 1972), pp. 102-124.

Stable URL:

http://links.jstor.org/sici?sici=0022-3808\%28197201\%2F02\%2980\%3A1\%3C102\%3AAUFWDC\%3E2.0.CO\%3B2-D

The Effect of Price Changes on the Demand and Supply of Separable Goods Masazo Sono

International Economic Review, Vol. 2, No. 3. (Sep., 1961), pp. 239-271.

Stable URL:

http://links.jstor.org/sici?sici=0020-6598\%28196109\%292\%3A3\%3C239\%3ATEOPCO\%3E2.0.CO\%3B2-M

NOTE: The reference numbering from the original has been maintained in this citation list. 
http://www.jstor.org

\section{LINKED CITATIONS}

- Page 12 of 13 -

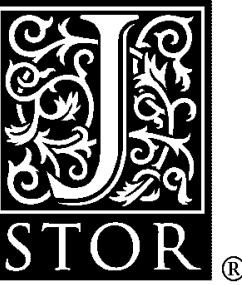

Linear Expenditure Systems and Demand Analysis: An Application to the Pattern of British Demand

Richard Stone

The Economic Journal, Vol. 64, No. 255. (Sep., 1954), pp. 511-527.

Stable URL:

http://links.jstor.org/sici?sici=0013-0133\%28195409\%2964\%3A255\%3C511\%3ALESADA\%3E2.0.CO\%3B2-D

The Empirical Implications of a Utility Tree

Robert H. Strotz

Econometrica, Vol. 25, No. 2. (Apr., 1957), pp. 269-280.

Stable URL:

http://links.jstor.org/sici?sici=0012-9682\%28195704\%2925\%3A2\%3C269\%3ATEIOAU\%3E2.0.CO\%3B2-1

The Utility Tree--A Correction and Further Appraisal

Robert H. Strotz

Econometrica, Vol. 27, No. 3. (Jul., 1959), pp. 482-488.

Stable URL:

http://links.jstor.org/sici?sici=0012-9682\%28195907\%2927\%3A3\%3C482\%3ATUTCAF\%3E2.0.CO\%3B2-4

\section{On the Estimation of Dynamic Demand Functions}

Lester D. Taylor; Daniel Weiserbs

The Review of Economics and Statistics, Vol. 54, No. 4. (Nov., 1972), pp. 459-465.

Stable URL:

http://links.jstor.org/sici?sici=0034-6535\%28197211\%2954\%3A4\%3C459\%3AOTEODD\%3E2.0.CO\%3B2-2

The Information Approach to Demand Analysis

H. Theil

Econometrica, Vol. 33, No. 1. (Jan., 1965), pp. 67-87.

Stable URL:

http://links.jstor.org/sici?sici=0012-9682\%28196501\%2933\%3A1\%3C67\%3ATIATDA\%3E2.0.CO\%3B2-F

An Economic Theory of the Second Moments of Disturbances of Behavioral Equations

Henri Theil

The American Economic Review, Vol. 61, No. 1. (Mar., 1971), pp. 190-194.

Stable URL:

http://links.jstor.org/sici?sici=0002-8282\%28197103\%2961\%3A1\%3C190\%3AAETOTS\%3E2.0.CO\%3B2-H

NOTE: The reference numbering from the original has been maintained in this citation list. 
http://www.jstor.org

\section{LINKED CITATIONS}

- Page 13 of 13 -

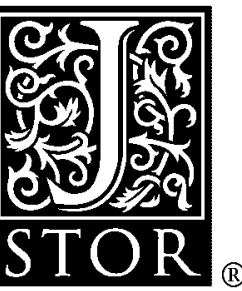

Substitution, Complementarity, and the Residual Variation around Engel Curves

H. H. Theil; H. Neudecker

The Review of Economic Studies, Vol. 25, No. 2. (Feb., 1958), pp. 114-123.

Stable URL:

http://links.jstor.org/sici?sici=0034-6527\%28195802\%2925\%3A2\%3C114\%3ASCATRV\%3E2.0.CO\%3B2-K

An Efficient Method of Estimating Seemingly Unrelated Regressions and Tests for Aggregation Bias

Arnold Zellner

Journal of the American Statistical Association, Vol. 57, No. 298. (Jun., 1962), pp. 348-368.

Stable URL:

http://links.jstor.org/sici?sici=0162-1459\%28196206\%2957\%3A298\%3C348\%3AAEMOES\%3E2.0.CO\%3B2-6

NOTE: The reference numbering from the original has been maintained in this citation list. 